Canadian

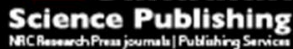

Canadian Geotechnical Journal Revue canadienne de géotechnique

\title{
Failure in anisotropic sensitive clays: a Finite Element study of the Perniö failure test
}

\begin{tabular}{|r|l|}
\hline Journal: & Canadian Geotechnical Journal \\
\hline Manuscript ID & cgj-2015-0313.R4 \\
\hline Manuscript Type: & Article \\
\hline Date Submitted by the Author: & 11-Feb-2017 \\
\hline Complete List of Authors: & $\begin{array}{l}\text { D'Ignazio, Marco; Norges Geotekniske Institutt } \\
\text { Lansivaara, T; Tampereen Teknillinen yliopisto } \\
\text { Jostad, Hans; Norges Geotekniske Institutt }\end{array}$ \\
\hline Keyword: & anisotropy, strain-softening, failure test, soft clays, FEM \\
\hline
\end{tabular}

SCHOLARONE ${ }^{\text {IM }}$

Manuscripts 
Title:

Failure in anisotropic sensitive clays: a Finite Element study of the Perniö failure test

\section{Authors:}

Marco D'Ignazio ${ }^{1}$

Tim Tapani Länsivaara ${ }^{2}$

Hans Petter Jostad ${ }^{3}$

${ }^{1}$ Norwegian Geotechnical Institute, NGI, Oslo, Norway. Address: Sognsveien 72, 0855 Oslo, Norway (email: marco.dignazio@ngi.no)

${ }^{2}$ Tampere University of Technology, Department of Civil Engineering, Tampere, Finland. Address: Korkeakoulunkatu 5, 33720, Tampere, Finland (email: tim.lansivaara@tut.fi)

${ }^{3}$ Norwegian Geotechnical Institute, NGI, Oslo, Norway. Address: Sognsveien 72, 0855 Oslo, Norway (email: hans.petter.jostad@ngi.no)

\section{Corresponding author:}

Marco D'Ignazio

Norwegian Geotechnical Institute, NGI,

Sognsveien 72, 0855 Oslo, Norway marco.dignazio@ngi.no 


\section{Abstract}

The railway network on coastal areas of Finland is predominantly located in soft clay areas. The undrained shear strength of such clays is generally low, highly anisotropic, rate dependent and it exhibits post-peak strain softening under undrained conditions. A full-scale failure test was performed by Tampere University of Technology in Perniö, Western Finland, in 2009. A shallow railway embankment built on a soft clay deposit was equipped with a loading structure and loaded to failure in about 30 hours. The embankment collapsed two hours after the last loading step.

In this study, data collected from the experiment is used, together with laboratory test results on high quality samples, to conduct advanced finite element analysis of the Perniö failure test.

The NGI-ADPSoft model is used for this purpose, which is capable of simulating the strainsoftening behavior of the clay.

Even though the observed rate effect is not taken into account in the analyses, the failure load can be predicted reasonably well. Good agreement is also observed for calculated displacements and failure mechanism with experimental observations.

\section{Keywords}

anisotropy; strain-softening; failure test; soft clays; FEM 


\section{INTRODUCTION}

The design of embankments on soft soils remains nowadays still a challenge for geotechnical engineers. Soft clays are characterized by very low permeability and very low undrained shear strength (even less than $10 \mathrm{kPa}$ near the ground surface). Undrained shear strength $\left(\mathrm{s}_{\mathrm{u}}\right)$ is a rather complex parameter, although it is in practice often considered as a constant throughout a soil layer. However, it highly depends on direction (stress-induced anisotropy) and rate of loading, as well as the initial stress state. Furthermore, for some clays (e.g. sensitive clays), significant post peak strain-softening occurs.

In order to investigate how a very soft subsoil influences the stability of an embankment, a fullscale embankment failure test in Perniö, Western Finland, was commissioned in 2009 by the Finnish Railway Authorities and conducted by Tampere University of Technology. A shallow railway embankment was built on a 3.5-4.5 m thick deposit of soft sensitive clay overlain by a 0.8$0.9 \mathrm{~m}$ dry crust and an old sand fill layer, and brought to failure in less than two days. The embankment was equipped with loading structure and the load was increased by filling containers with sand. The embankment failed at a measured distributed vertical force of $217 \mathrm{kN} / \mathrm{m}$, two hours after the last loading step (Lehtonen et al. 2015).

The extensive amount of data gathered from the experiment has been exploited to conduct advanced studies on the behavior of Finnish soft clays (Mansikkamäki et al. 2011; Länsivaara et al. 2011; Mansikkamäki and Länsivaara 2012; Länsivaara et al. 2014; D’lgnazio et al. 2014; D’Ignazio and Länsivaara 2015; Mansikkamäki 2015; D’Ignazio 2016).

The common practice in Finland is to perform total stress stability analyses using Limit Equilibrium Method (LEM), based on the isotropic $s_{u}$ measured from the field vane (FV) test. However, features such as post-peak softening cannot be taken into account in LEM, even though it has a major impact on the actual soil resistance.

The aim of this paper is to back-analyze the Perniö full-scale test using the Finite Element Method (FEM). Data from triaxial compression (TXC), triaxial extension (TXE), FV and oedometer tests on Perniö sensitive clay is exploited to derive parameters for advanced FE analyses. 
In order to model $\mathrm{s}_{\mathrm{u}}$ anisotropy and strain-softening behavior of Perniö clay, the anisotropic total stress constitutive model NGI-ADPSoft (Grimstad et al. 2010), developed by the Norwegian Geotechnical Institute (NGI) and implemented in PLAXIS 2D AE (PLAXIS 2012) finite element (FE) code, was adopted to model the soft clay layers.

The NGI-ADPSoft model is based on the anisotropic "ADP" undrained shear strength concept (Bjerrum 1973). The $s_{u}$ profiles for active $(A)$, direct simple shear $(D)$ and passive $(P)$ loading (stress paths) are given as input data (Fig. 1).

First, in this study, background information on $s_{u}$ anisotropy and strain-softening is given, followed by a description of the Perniö failure test and the test site. Then, the NGI-ADPSoft model is presented in some detail. After that, the finite element model in PLAXIS and the material parameters are discussed. Finally, calculation results are compared with measurements from the full-scale experiment, with emphasis on the failure mechanism. Lastly, sensitivity analysis on the model parameters and effects of strain rate are considered.

\section{BACKGROUND}

\section{Strain-softening}

On coastal areas of Finland, the railway network is to a large extent located in soft clay areas. Finnish soft clays are mostly normally consolidated or slightly over consolidated and they can be often defined as "sensitive". Sensitive clays are classified based on their sensitivity $\left(\mathrm{S}_{t}\right)$ value, defined as $S_{t}=s_{u} / s_{u}{ }^{r e}$, where $s_{u}$ is the peak undrained shear strength and $s_{u}{ }^{r e}$ is the remolded undrained shear strength.

According to SFS-EN ISO 14688-2 (2004), the sensitivity is low when $S_{t}<8$, medium when $S_{t}=8$ -30 or high when $S_{t}>30$.

Sensitive clays are characterized by an open soil structure with some bonds (e.g. Rosenqvist 1953, 1966). The natural water content of these clays can be considerably higher than the liquid limit (e.g. D'Ignazio et al. 2016). The maximum strength is maintained by the undisturbed soil until it is loaded undrained beyond the peak strength. Then, the structure collapses and the resistance 
reduces dramatically. Such a phenomenon is called strain-softening: "When subjected to a shear or a consolidation test, the clay shows a brittle behavior characterized by the fact that at a very small strain a critical stress level is reached, beyond which the magnitude and rate of deformations are large.” (Bjerrum 1973).

\section{Progressive failure mechanism and FE modeling}

When a slope stability analysis is carried out without including anisotropy and/or strain-softening, one assumes that a given shear strength, independent of strain level and direction of loading, is mobilized along a potential failure surface. However, based on the findings of, e.g., Karlsrud et al. (1984), Bernander (2000) and Gylland (2012), this is an erroneous assumption for soft sensitive clays. Indeed, the mobilized shear strength along the potential failure surface is governed by the actual stress-strain curve of the soil. This would suggest the failure mechanism to be progressive in nature.

A simple but comprehensive description of the progressive failure mechanism is given by Skempton (1964): when in a clay mass the peak strength is passed at some particular point, the strength at that point will start decreasing and additional stress will be transmitted at some other point in the soil mass, causing the peak to be passed at that point too. As a direct consequence, a real chain reaction is established until a slip surface will develop further in the soil because of the strain-softening behavior. Eventually, when failure occurs, the shear strength will reach its residual value along the whole slip surface after sufficient deformation has occurred along the full length of the failure surface. Skempton (1964) also pointed out how failure may occur even before the residual strength is attained throughout the clay. However, once failure has started, the average $s_{u}$ along the slip surface will fall towards its residual value.

In order to model and study a progressive type of failure it is necessary to take the strain-softening behavior into account. Accounting for strain-softening effects in stability analyses is a challenging issue. Over the last 15 years, FE analyses using advanced soil models capable of describing the undrained post-peak behavior of soft Norwegian clays at large strains have been proposed (e.g., 
Andresen et al. 2002; Jostad and Andresen 2004; Grimstad et al. 2010; Jostad and Grimstad 2011).

When peak strength is reached, local failure and strain localization will occur and shear bands will develop in the initially homogeneous soil. When the shear strains are localized, all the further deformation will tend to concentrate in these zones or bands (Desrues and Viggiani 2004).

Since the shear strain and thus the effect of undrained strain-softening increases with reducing shear band thickness, a regularization technique is needed so that both thickness and orientation of the shear band will not be dependent on the adopted mesh. In this way, the element size will not be acting as an internal length parameter and the thickness of the shear band will not reach its minimum size governed by the mesh (Bazant 1976; Pietruszczak and Mròz 1981). In addition, mesh refinement without a regularization technique will affect both peak capacity and global postpeak response (Gylland 2012). A detailed review of different regularization techniques is, for instance, given by De Borst et al. (1993).

\section{Anisotropy}

Another major factor, typical of soft sensitive clays, to be considered is the dependency of $s_{u}$ on the stress path followed during undrained shearing, namely the stress-induced anisotropy. Sources of stress-strain-strength anisotropy can be found in stress-induced anisotropy as well as inherent (material) anisotropy (Bjerrum 1973; Hicher et al. 2000; Karstunen et al. 2005; Länsivaara 1999; Koskinen 2014).

In undrained stability and bearing capacity problems, strength anisotropy is a factor which ought to be taken into account, since the distribution of $s_{u}$ is known to vary along the slip surface according to the direction of the major principal stress (Bjerrum 1973).

For instance, in Finnish engineering practice, embankment stability analyses are commonly conducted as total stress analyses using the isotropic $s_{u}$ determined from the FV test. However, $s_{u}$ of Finnish clays is highly anisotropic (Karstunen et al. 2005; Koskinen 2014; Mansikkamäki 2015; Lehtonen 2015). In Norway and Sweden, $s_{u}$ anisotropy is often accounted for in practice. 
Undrained shear strength anisotropy can be reliably measured in the laboratory through triaxial (or plane strain) compression and extension tests together with direct simple shear (DSS) tests, as long as the specimens are consolidated anisotropically to the in situ stress level before shearing (Bjerrum and Landva 1966; Berre 1969; Bjerrum 1973).

When a soft clay specimen is sheared in compression (active, triaxial or plane strain) or in extension (passive, triaxial or plane strain), the behavior observed may be quite different, not only in terms of measured $\mathrm{s}_{\mathrm{u}}$ (strength anisotropy), but also in terms of shear strains needed to mobilize peak strengths according to the major principal stress direction (strain anisotropy). In general, for normally consolidated to slightly overconsolidated soft clays, the shear strain needed to mobilize peak strength when the inclination of major principal stress is $0^{\circ}$ from the vertical (active), is lower than the shear strain needed to mobilize peak strength when the inclination of major principal stress is $90^{\circ}$ from the vertical (passive). The DSS peak strength is normally mobilized at a strain level between that of active and the passive, as suggested by the experimental observations reported by Karlsrud and Hernandez-Martinez (2013).

According to Bjerrum (1973), Ladd et al. (1977), Larsson (1980) and Jamiolkowski et al. (1985), the $\mathrm{s}_{\mathrm{u}}$ anisotropy is highest when the clay has a low plasticity and it becomes more isotropic with increasing plasticity. This means that the anisotropy ratio $\mathrm{s}_{\mathrm{u}}{ }^{\mathrm{P}} / \mathrm{s}_{\mathrm{u}}{ }^{\mathrm{A}}$ (see e.g. Grimstad et al. 2012), where $\mathrm{S}_{\mathrm{u}}{ }^{\mathrm{P}}$ and $\mathrm{S}_{\mathrm{u}}{ }^{\mathrm{A}}$ represent the peak $\mathrm{S}_{\mathrm{u}}$ from triaxial or plane strain extension (superscript $\mathrm{P}$ for passive) and compression tests (superscript A for active), respectively, increases with increasing liquid limit $\left(\mathrm{W}_{\mathrm{L}}\right)$ and plasticity index $(\mathrm{PI})$ of the soil. This trend was also verified for the anisotropy ratio in DSS $\left(\mathrm{s}_{\mathrm{u}}{ }^{\mathrm{DSS}} / \mathrm{s}_{\mathrm{u}}{ }^{\mathrm{A}}\right)$ (Bjerrum 1973; Ladd et al. 1977; Larsson 1980; Jamiolkowski et al. 1985). However, such a trend might not be totally justified since, according to Mayne (1983) and Won (2013), it is based on limited test results and might have been strongly influenced by the definition of failure in extension tests (Won 2013). A definition of strength anisotropy dependent on PI should be carefully verified by thorough considerations on site characteristics, clay structure, mineralogy, soil history and spatial variability (Won 2013).

Thakur et al. (2014) collected data on anisotropic $\mathrm{s}_{\mathrm{u}}$ of Norwegian clays. A positive trend between $\mathrm{s}_{\mathrm{u}}{ }^{\mathrm{P}} / \mathrm{s}_{\mathrm{u}}{ }^{\mathrm{A}}$ and $\mathrm{s}_{\mathrm{u}}{ }^{\mathrm{DSS}} / \mathrm{s}_{\mathrm{u}}{ }^{\mathrm{A}}$ and PI was observed. 
Several clays from different parts of the world have been studied for research purposes and the anisotropy ratio has been characterized through numerous laboratory tests. In Table 1 values for $\mathrm{S}_{\mathrm{u}}{ }^{\mathrm{DSS}} / \mathrm{S}_{\mathrm{u}}{ }^{\mathrm{A}}$ and $\mathrm{s}_{\mathrm{u}}{ }^{\mathrm{P}} / \mathrm{s}_{\mathrm{u}}{ }^{\mathrm{A}}$ reported by some authors are summarized.

The dependency of $s_{u}$ on the stress path followed during undrained loading is known to be a function of the shape and the inclination of the initial yield surface. The dependency on stress path is greater when the initial yield surface is rotated. A rotated yield surface indicates that an initial material anisotropy is present. According to Länsivaara $(1995,1999)$, an approximation of the yield surface can be made if the critical state friction angle $\left(\phi^{\prime}\right)$ and the preconsolidation pressure $\left(\sigma_{p}^{\prime}\right)$ are known. The yield surface can be assumed to be ellipsoidal in shape; its size is determined by $\sigma_{p}^{\prime}$

\section{PERNIÖ FAILURE TEST}

\section{Site description}

The general stratigraphy of the test area is shown in the cross section provided in Fig. 2. As shown (from top down), an old $1.5 \mathrm{~m}$ thick fill made of sand and gravel lays on a 0.8-0.9 $\mathrm{m}$ thick weathered clay crust layer, followed by a 3.5 to $4.5 \mathrm{~m}$ thick soft clay layer. The underlying varved silty clay layer composed of thin clay, silt, and sandy silt layers extends for a thickness of approximately $1.5 \mathrm{~m}$ over a dense sand layer 2 to $8 \mathrm{~m}$ thick. The groundwater table was found at a depth of about $1.3 \mathrm{~m}$ below the ground surface.

The general characteristics of Perniö clay are presented in Fig. 3 and summarized in Table 2. Perniö clay is highly sensitive (average $S_{t} \approx 42$ ). From the Fall Cone $(F C)$ test, $s_{u}{ }^{r e}$ values lower than $0.5 \mathrm{kPa}$ were observed. A clay content varying from 48 to $81 \%$ was measured in the soft clay. The natural water content $(w)$ ranges from $48 \%$ to $109 \%$, while the liquid limit $\left(w_{L}\right)$ varies from 38 to $82 \%$. Plastic limit $\left(w_{P}\right)$ tests performed on samples collected slightly outside of the test area suggest that $w_{P}$ of Perniö clay varies in the range $29-36 \%$. Therefore, PI of the soft subsoil at the test site falls into the interval $36-49 \%$ (Lehtonen et al. 2015). The soft clay is slightly 
overconsolidated, showing overconsolidation ratio $(\mathrm{OCR})$ values generally lower than 1.5 . The measured $\sigma_{p}^{\prime}$ values in Fig. 3 are based on constant rate of strain (CRS) oedometer tests. In the top portion of the clayey layer right below the dry crust (hereinafter called "stiff clay"), OCR reaches values higher than 2 .

Field vane shear test shows $s_{u}$ of 9 to $13 \mathrm{kPa}$ near the top of the soft clay layer with an average strength increase with depth of $1.15 \mathrm{kPa} / \mathrm{m}$. Therefore, according to Leroueil et al. (1990), the Perniö clay can be classified as a "very soft" clay $\left(\mathrm{s}_{\mathrm{u}}=10-20 \mathrm{kPa}\right)$.

At the elevation below about $3 \mathrm{~m}$ the scatter of $\sigma_{p}^{\prime}$ is higher than in the top part (Fig. 3 ), where the measured points are grouped fairly well. According to Fig. $3, S_{t}$ in this layer may be higher than in the upper layer, even though this is suggested by only one data point.

A shallow railway embankment constituted of crushed ballast, $0.55 \mathrm{~m}$ thick, $3.2 \mathrm{~m}$ wide (top) and about $60 \mathrm{~m}$ long was built for this test on top of the existing sand fill layer. A ditch was excavated at one side in order to control the direction and the extent of failure.

The embankment was equipped with a loading structure and four containers were placed and filled with sand by means of a conveyor belt. The conveyor belt was placed at safe distance so that there would not have been any interaction with the containers in case of failure. The continuous filling process was designed so that the load was distributed homogeneously in all the containers. The sand fill was continuously delivered by the conveyor belt to containers one to four and vice versa.

The embankment behavior was expected to be mostly governed by the soft clay, which was highly instrumented and monitored during the whole duration of the test and where the majority of the available and exploitable measurements come from.

The extensive instrumentation (Lehtonen 2011; Lehtonen et al. 2015) consisted of: 37 pore pressure gauges positioned in four groups: under the embankment centerline, under the embankment toe, halfway between the embankment and the ditch and next to the ditch; 27 surveying prisms on the soil surface and the loading containers; 9 automatic two axis inclinometers, installed in three cross sections; three settlement tubes with a total of 53 pressure transducers; six total stress earth pressure gauges under the embankment; 76 slip surface 
measurement tubes with surveying points on the surface; 32 strain gauges on the frameworks for weighing the containers. The instrumentation layout is shown in Fig. 4.

The loading process lasted about 30 hours, when the measured distributed vertical force reached about $217 \mathrm{kN} / \mathrm{m}$ for cars 2 and 3 . Given that the loading area was $2.5 \mathrm{~m}$ wide, a bearing pressure of about $87 \mathrm{kPa}$ was measured at the end of loading. The embankment failed two hours after the last loading step. For a detailed description of the experiment, see Lehtonen et al. (2015).

The Perniö failure test represents a case of a quickly loaded embankment if compared to other failure tests e.g. the Saint Alban test embankment (La Rochelle et al. 1974), which was brought to failure in about ten days.

\section{Failure mechanism and observations}

According to Lehtonen et al. (2015) the best estimate of the shape of the failure zone comes from the pre-failure pore pressure readings, coupled with inclinometer readings. In general, a distinct slip surface was difficult to detect. A shear zone seems to develop starting from behind the railway sleepers, reaching its lowest level in the soft clay layer under the embankment toe, before gently bending up and emerging at the bottom of the ditch. Based on the interpreted failure mechanism, shear seems to occur differently over three distinct zones along the shear band (Fig. 5): an active zone underneath the area of application of the load, a direct shear zone beneath the embankment toe and a passive zone moving upwards and outwards toward the excavated ditch.

Perniö full scale test was characterized by an undrained creep type of failure (Lehtonen et al. 2015), since rupture has occurred under the applied maximum load only after a certain time had elapsed from the last loading step. During that time (approximately two hours), both excess pore pressures and rate of excess pore pressures have increased until failure occurred (Fig. 6). Probably, the soil was initially subjected to a local failure below the embankment which developed further over time. Failure seemed to have occurred under undrained condition, as no dissipation of pore pressure could be observed (Fig. 6). 
Studies carried out by Arulandan et al. (1971) and Holzer et al. (1973) have shown that a threshold level of deviator stress exists beyond which undrained creep will lead to an increase in rate of strain and pore pressure until rupture. Time to failure is inversely proportional to the ratio of stress level reached to that of the threshold deviator stress.

When a soft clay is subjected to a "fast" undrained loading, the stress-strain response will be stiffer than in a "slow" type of loading (Berre and Bjerrum 1973; Lefebvre and Leboeuf 1987; Graham et al. 1983a; Leroueil et al. 1985). This concept is shown in Fig. 7. The effective stress path A-B may ideally describe a "standard" or "slow" test, while the stress path A-C-E would be representative of a rapidly loaded sample. What probably happened in the field test, could be described by the stress path A-C-D: the soil was quickly loaded up to a deviator stress level beyond the threshold, which did not cause failure straight away, but only after a certain elapsed time because of undrained creep, under a given constant load. In addition, if the loading process had continued further, the soil may have failed at a higher load than $87 \mathrm{kPa}$ (point E).

The evolution of shear strain versus time and applied load (q) is shown in Fig. 8. Measured horizontal displacements from inclinometers L2P1, L2P2 and L2P3 were used to derive the magnitude of shear strain during the test, according to eq. (1):

$$
\gamma=\frac{\Delta u_{x}}{\Delta z}
$$

where $\gamma$ is the shear strain, $\Delta u_{x}$ is the incremental horizontal displacement measured by the inclinometer between two consecutive measurement points and $\Delta \mathrm{z}$ is the vertical distance between the two points.

The evolution of shear strain with time at points A, B, C (located as shown in Fig. 5) from inclinometers L2P1, L2P2, L2P3, respectively, is shown in Fig. 8.

During the first day of loading, when the load was lower than $24 \mathrm{kPa}$, only very small deformations could be observed. A load of $24 \mathrm{kPa}$ was maintained constant during the night, over a period of time of about 14 hours. However, when the load-to-failure process started after the night, both strains and rate of strain increased until the end of loading, and later increase until failure, within 
the time-frame when the applied load was kept constant and equal to $87 \mathrm{kPa}$. The evolution of shear strain with time seems to change about 3-4 hours before failure (inclinometer L2P1), simultaneously with yielding of the soft clay. A similar yield point was identified by Lehtonen et al. (2015) from the pore pressure readings (Fig. 6). Fig. 8 would suggest that during the experiment, the shear strain rate increased by over a tenfold, thus justifying the rather high failure load achieved.

For a given time step, different strain levels mobilized at different locations where the inclinometers were placed, would suggest a progressive type of mechanism leading to failure (Fig. 8).

\section{CONSTITUTIVE MODELS}

The NGI-ADP soil model (Grimstad et al. 2012) is a total stress elasto-plastic model based on an anisotropic Tresca failure criterion. The anisotropic behavior follows the ADP framework by Bjerrum (1973), where the $s_{u}$ profiles for active $(A)$, direct simple shear $(D)$ and passive $(P)$ stress paths are given directly as input parameters. The non-linear hardening curves are described by input of the peak $\mathrm{s}_{\mathrm{u}}$ and corresponding shear strains in the three directions of shearing represented by TXC, DSS and TXE, as shown in Fig. 9. A special version of the model, the NGI-ADPSoft (Grimstad et al. 2010), accounts for the anisotropic post-peak strain softening behavior, often observed during undrained tests on soft sensitive clays. The softening curves are described by input of the residual $s_{u}$ and corresponding shear strains in the same three directions of shearing, as shown in Fig. 10. By interpolation between the three input curves, the model is able to model the anisotropic behavior of the clay for a general 3D stress state. The model chooses the stresspath to follow based on the orientation $(\theta)$ of the major principal stress from the vertical. For $\theta=0^{\circ}$, the model assumes pure compression, while for $\theta=90^{\circ}$, it assumes pure extension.

The undrained triaxial tests used to establish the input parameters, should be consolidated anisotropically to the assumed in situ effective stresses $\left(\mathrm{CK}_{0} \mathrm{UC}\right.$ and $\mathrm{CK}_{0} \mathrm{UE}$ tests). The triaxial curves in Fig. 10 therefore start from the initial shear stress $\tau_{0}$. The initial inclination of the curves 
comes from the initial shear modulus $\mathrm{G}_{0}$, which also defines the magnitude of the elastic strain components.

The model assumes that $\mathrm{s}_{\mathrm{u}}$ varies linearly with depth within a soil layer. $A$ constant $\mathrm{s}_{\mathrm{u}}{ }^{\mathrm{A}}$ ref at a reference depth $y_{\text {ref }}$, together with a strength increase parameters $s_{u}{ }^{A}$ inc, define the $s_{u}$ profile in the soil layer. Furthermore, the reference depth $y_{\text {ref }}$ may be given by a reference point $x_{\text {ref }}$ and an inclination $\Delta \mathrm{y}_{\text {ref }} / \Delta \mathrm{x}$, for inclined clay layers.

In this study, for the sake of simplicity and because of lack of plane strain tests, the plane strain "A=active" behavior is assumed to be equal to the triaxial compression behavior, and correspondingly, the plane strain "P=passive" behavior is assumed to be equal to the triaxial extension behavior, as also suggested by e.g. Jostad et al. (2014).

The strain-softening response requires a regularization method so that numerical problems and mesh dependency are avoided. Therefore, the NGI-ADPSoft model includes the "over non-local strain" formulation proposed by Brinkgreve (1994) that is based on the "non-local strain" approach formulated by Eringen (1981). This method introduces an internal length scale to overcome mesh dependency. The "over non-local" strain is calculated as an integrated average shear strain within a specified zone around the actual Gauss point, governed by the input of the internal length scale $\left(l_{\text {int }}\right)$. Then, as long as $l_{\text {int }}$ is selected sufficiently large compared to the element size, the shear band will be larger or equal to the element size, thus avoiding the shear band thickness to be affected by the orientation and size of the elements. The thickness of the shear band is controlled by $l_{\text {int }}$ together with a parameter $\alpha$. The thickness of the shear band $\left(t_{s b}\right)$ is then calculated from eq. (2) (Brinkgreve 1994):

$$
t_{s b}=\pi \cdot l_{\text {int }} \cdot\left[\ln \left(\frac{\alpha}{\alpha-1}\right)\right]^{\frac{1}{2}}
$$

According to Vermeer and Brinkgreve (1994) and Jostad and Grimstad (2011), $\alpha=2.00$ represents a recommended value for the numerical integration of the non-local strain. The effective shear band thickness $t_{s b}$ is then 2.62 times $l_{\text {int }}$. 
The main advantage of using the over non-local regularization technique is that the implementation into a non-linear finite element program can be easily done, since no reformulation of the governing finite element equations is needed. This is generally required for the other types of regularization techniques. The regularization based on the non-local strain approach is fully solved at the material point level, with only additional information on the strains in the neighboring elements. Therefore, the regularization can be accounted for by a user-defined material model implemented in a commercial finite element program (Grimstad et al. 2010).

\section{Formulation of NGI-ADPSoft soil model}

The formulation of the NGI-ADPSoft soil model is based on an anisotropic approximated Tresca yield criterion (Grimstad et al. 2012), where the yield function $F$ is defined by eq. (3):

$$
F=\sqrt{H(\omega) \hat{J}_{2}}-\kappa_{1}\left(1-\kappa_{2}\right) \frac{{s_{u}}^{A}+s_{u}{ }^{P}}{2}-\kappa_{2} \frac{{s_{u r}}^{A}+s_{u r}{ }^{P}}{2}=0
$$

Where $\hat{J}_{2}$ is a modified second deviatoric invariant (Grimstad et al. 2012), the function $H(\omega)$ (eq.

(4)) approximates the Tresca criterion and the hardening parameters $\kappa_{1}$ and $\kappa_{2}$ are computed from eq. (5) and eq. (6).

$$
H(\omega)=\cos ^{2}\left[\frac{1}{6} \arccos \left(1-2 a_{1} \omega\right)\right]
$$

Where $\omega$ is a function of $\hat{J}_{2}$ and the modified third deviatoric invariant $\hat{J}_{3}$ (Grimstad et al. 2012), $a_{1}$ is the rounding ratio (Grimstad et al. 2012), which is set equal to 0.99 (default value).

$$
\kappa_{1}=2 \frac{\sqrt{\gamma^{p} / \gamma_{p}^{p}}}{1+\gamma^{p} / \gamma_{p}^{p}}, \quad \text { for } \gamma^{\mathrm{p}}<\gamma_{\mathrm{p}}^{\mathrm{p}}, \kappa_{1}=1 \text { for } \gamma^{\mathrm{p}} \geqslant \gamma_{\mathrm{p}}^{\mathrm{p}}
$$

$$
\kappa_{2}=\left(\frac{\gamma^{p}-\gamma_{p}^{p}}{\gamma_{r}^{p}-\gamma_{p}^{p}}\right)^{c_{1}}\left(2-\frac{\gamma^{p}-\gamma_{p}^{p}}{\gamma_{r}^{p}-\gamma_{p}^{p}}\right)^{c_{2}} \text { for } \gamma_{\mathrm{p}}^{\mathrm{p}}<\gamma^{\mathrm{p}}<\gamma_{\mathrm{r}}^{\mathrm{p}}, \kappa_{2}=0 \text { for } \gamma^{\mathrm{p}} \leqslant \gamma_{\mathrm{p}}^{\mathrm{p}} \text {, else } \kappa_{2}=1
$$


The second deviatoric invariant $\hat{J}_{2}$ is based on a modified stress vector (Grimstad et al. 2010) that accounts for the anisotropy in strength and the initial stress conditions $\left(\tau_{0}\right)$. The strains $\gamma^{p}, \gamma_{p}^{p}$ and $\gamma_{r}^{p}$ are the plastic shear strain, plastic "peak" shear strain and plastic "residual" shear strain. The softening parameter $\kappa_{2}$ (eq. (6)), in this newest version of the model (NGI 2011), is controlled by two curve fitting parameters $c_{1}$ and $c_{2}$. For $c_{1}=1$ and $c_{2}=0$, the softening curve will be linear from peak to residual shear strain (Fig. 11).

The parameters $\gamma_{p}^{p}$ and $\gamma_{r}^{p}$ are stress path dependent in a similar way as $s_{u}$. The interpolation function for $\gamma_{p}^{p}$ and $\gamma_{r}^{p}$ is described in detail in Grimstad et al. (2010) and in NGI (2011). The input parameters for the NGI-ADPSoft model are summarized and briefly described in Table 4.

\section{MODEL PARAMETERS FOR FINITE ELEMENT ANALYSES}

\section{Soft clay}

The determination of the model parameters for NGI-ADPSoft model was carried out by analyzing the results of anisotropically consolidated TXC and TXE tests on Perniö clay together with in situ tests. Measured data from 13 triaxial tests on $86 \mathrm{~mm}$ diameter tube samples and $32 \mathrm{FV}$ tests were exploited to estimate the soil parameters to be used in the FE calculation. Tube samples for the triaxial tests were taken in 2013 from an area located about $50 \mathrm{~m}$ off the test area, with the purpose of evaluating the $s_{u}$ anisotropy of Perniö clay and the determination of $s_{u}$ at different OCR values (Lehtonen 2015).

Undrained DSS tests were not available for Perniö clay, since DSS tests are not used in Finland. According to Jamiolkowski et al. (1985) and Chandler (1988) the DSS strength is to some extent comparable with the FV shear strength. It is known how FV test is affected by uncertainty, especially in soft soil deposits when performed without casing (Ortigao and Collett 1988; Mansikkamäki 2015; Selänpää et al. 2017 In Press). Nevertheless, FV data from the initial soil investigation at Perniö site were exploited to verify the DSS strength of Perniö clay predicted by some existing correlations. 
Characteristics of Perniö clay are summarized in Tab 2. 29 constant rate of strain (CRS) oedometer tests on tube samples were performed in order to evaluate $\sigma_{p}^{\prime}$ of Perniö clay. The preconsolidation pressure $\sigma_{p}^{\prime}$ is identified according to Kolisoja et al. (1989). The CRS tests were conducted at standard constant speed equal to $0.0015 \mathrm{~mm} / \mathrm{min}(0.6 \% / \mathrm{h})$ and no correction was applied to $\sigma_{p}^{\prime}$ for strain rate. According to the oedometer test results, $\sigma_{p}^{\prime}$ in the soft clay (Fig. 3) decreases with depth for about $1 \mathrm{~m}$ below the dry crust before increasing with depth. The preconsolidation pressure $\sigma_{p}^{\prime}$ was found to be higher than the in situ stress, typically by about 18 $\mathrm{kPa}$, on average. The variation of $\sigma_{\mathrm{p}}^{\prime}$ with depth would suggest that also $\mathrm{s}_{\mathrm{u}}$ is expected to decrease until about $z=5 \mathrm{~m}$ and then increase linearly with depth. The difference between $\sigma_{p}^{\prime}$ and $\sigma_{\mathrm{v} 0}^{\prime}$ is assumed not to be varying towards the ditch, as the thickness of the old fill layer was constant throughout the whole area before the ditch was excavated.

The measured peak $s_{u}$ from TXC and TXE normalized with respect to the vertical effective stress $\left(\sigma_{v}^{\prime}\right)$ are compared to existing correlations for anisotropic $s_{u}$ of Scandinavian clays (Larsson et al. 2007; Karlsrud and Hernandez-Martinez 2013).

The correlations studied are all based on the SHANSEP framework (Ladd and Foott 1974, eq. (7)) and constructed from the results of $\mathrm{CK}_{0} \mathrm{UC}, \mathrm{CK}_{0} \mathrm{UE}$ and $\mathrm{CRS}$ oedometer tests.

$$
\frac{s_{u}}{\sigma_{v}^{\prime}}=S\left(O C R^{m}\right)
$$

The parameter "S" represents the undrained strength ratio $\left(\mathrm{s}_{\mathrm{u}} / \sigma_{\mathrm{v}}{ }_{\mathrm{v}}\right)$ for the normally consolidated state and "m" is a material dependent exponent.

According to Karlsrud and Hernandez-Martinez (2013), the SHANSEP parameters "S" and "m" correlate with the natural water content of the clay $(\mathrm{w})$. The fitted average anisotropic $\mathrm{s}_{\mathrm{u}}$ based on a large number of tests on block samples from different sites in Norway can be described as follows, from eq. (8), (9) and (10):

$$
\frac{s_{u}{ }^{A}}{\sigma^{\prime}{ }_{v}}=(0.27+0.1 w) O C R^{(0.58+0.33 w)}
$$




$$
\begin{aligned}
& \frac{s_{u}{ }^{D S S}}{\sigma^{\prime}{ }_{v}}=(0.14+0.18 w) O C R^{(0.35+0.77 w)} \\
& \frac{s_{u}{ }^{P}}{{\sigma^{\prime}}^{\prime}}=(0.26 w) O C R^{(0.86+0.30 w)}
\end{aligned}
$$

where $\mathrm{s}_{\mathrm{u}}{ }^{\mathrm{A}}, \mathrm{s}_{\mathrm{u}}{ }^{\mathrm{DSS}}$ and $\mathrm{s}_{\mathrm{u}}{ }^{\mathrm{P}}$ are the peak shear strengths from TXC, DSS and TXE tests, respectively. Larsson et al. (2007) suggested correlations for anisotropic $s_{u}$ of soft Scandinavian clays as a function of $W_{L}$ of the soil.

Based on eq. (7), Larsson et al. (2007) proposed expressions to derive "S" from curve fitting of test results on Scandinavian inorganic clays, while " $m$ " is maintained constant and equal to 0.8 , which is consistent with the studies done by Jamiolkowski et al. (1985) and Ladd (1991).

For triaxial compression, " $S$ " seems independent of $w_{L}$, and it was observed to be equal to 0.33 (Larsson et al. 2007). Therefore, the anisotropic $s_{u}$ can be expressed as in eq. (11), (12) and (13):

$$
\begin{aligned}
& \frac{s_{u}{ }^{A}}{\sigma^{\prime}{ }_{v}}=0.33 O C R^{0.8} \\
& \frac{s_{u}{ }^{D S S}}{\sigma^{\prime}{ }_{v}}=\left(0.125+0.205 w_{L} / 1.17\right) O C R^{0.8} \\
& \frac{s_{u}{ }^{P}}{{\sigma^{\prime}}^{\prime}}=\left(0.055+0.275 w_{L} / 1.17\right) O C R^{0.8}
\end{aligned}
$$

The calculated average $w_{L}$ of the soft clay in Perniö is $57 \%$ (Lehtonen et al. 2015).

As clearly shown by the laboratory test results (Fig. 12), the variation of $\mathrm{s}_{\mathrm{u}} / \sigma_{\mathrm{v}}^{\prime}$ as a function of the OCR can be fairly well described by the transformation model of eq. (8), using $w=90 \%$, for TXC and by the transformation model of eq. (13) for TXE, using $w_{L}=57 \%$.

For $w=90 \%$, the correlations proposed by Karlsrud and Hernandez-Martinez (2013) can describe quite well $\mathrm{S}_{\mathrm{u}}{ }^{\mathrm{A}}$ from Lehtonen (2015), while they clearly overestimate $\mathrm{S}_{\mathrm{u}}{ }^{\mathrm{P}}$ from Lehtonen (2015).

The framework proposed by Larsson et al. (2007) (eq. (11), (12), (13)) seems to correlate relatively well with the measurements, although it underpredicts some of the TXC results.

The estimated anisotropy ratio $\mathrm{s}_{\mathrm{u}}{ }^{\mathrm{P}} / \mathrm{s}_{\mathrm{u}}{ }^{\mathrm{A}}$ is about 0.5 , based on eqs. (8), (10), (11) and (13). 
The DSS strength was derived by comparing FV measurements with existing correlations (eq. (9), (12), (14), (15)). Jamiolkowski et al. (1985) proposed, for the in situ mobilized undrained shear strength $\left[\mathrm{s}_{\mathrm{u}}(\mathrm{mob})\right]$, roughly corresponding to DSS conditions (eq. (13)):

$$
\frac{s_{u}(m o b)}{\sigma_{v}^{\prime}}=0.23 O C R^{0.8}
$$

Ching and Phoon (2012) proposed a framework for peak $s_{u}$ of structured clays from $F V$ and unconfined compression (UC) tests, where $S_{u}(m o b)$ is derived based on OCR and $S_{t}($ eq. (14)):

$$
\frac{s_{u}(m o b)}{\sigma_{v}^{\prime}}=0.229 O C R^{0.820} S_{t}^{0.121}
$$

The measured uncorrected FV strength in Perniö varies between 9-13 kPa on top of the soft layer, increasing with depth about $1.15 \mathrm{kPa} / \mathrm{m}$. It should be pointed out though that the FV test is performed rather quickly, at a rate of strain that is quite high $\left(\sim 60 \% \mathrm{~h}^{-1}\right.$, Ching et al. 2013) compared with conventional DSS tests $\left(\sim 1 \% \mathrm{~h}^{-1}\right)$. For this reason, measured values must be corrected in order to account for rate effect (e.g. Bjerrum 1972) based on PI of the clay. Field vane data points are corrected for plasticity as suggested by the Finnish guidelines for stability analysis (Ratahallintokeskus 2005). The average correction factor applied to the FV strength data points is equal to 0.95 .

In Fig. 13 the normalized corrected FV strength for Perniö is plotted against the OCR. From Fig. 13 it is clear that the measured data disagree with the correlations proposed by Ching and Phoon (2012) and Karlsrud and Hernandez-Martinez (2013). Even though the measurements show evident scatter, the correlations proposed by Jamiolkowski et al. (1985) and Larsson et al. (2007) seem the most representative of the trend observable from the measured strength points. The trendlines suggested by eq. (12), for $\mathrm{w}_{\mathrm{L}}=57 \%$, and eq. (14) seem to reasonably adapt to the data points for $\mathrm{OCR}<2$. 
Finally, $\mathrm{s}_{u}{ }^{D S S} / \mathrm{s}_{u}{ }^{A}$ is assessed to be approximately equal to 0.65 , based on eq. (8) and eq. (12). The assumption of an average $\mathrm{s}_{\mathrm{u}}{ }^{\mathrm{DSS}} / \mathrm{s}_{\mathrm{u}}{ }^{\mathrm{A}}$ of about 0.65 is consistent with that reported by Jamiolkowski et al. (1985), Karlsrud et al. (2005), Karlsrud and Hernandez-Martinez (2013) and Thakur et al. (2014).

Fig. 14 shows the fit of NGI-ADPSoft model to CAUC and CAUE tests on Perniö clay reported by Lehtonen (2015). Shear strain at peak is assumed for $\mathrm{s}_{\mathrm{u}}{ }^{\text {DSS }}$ by selecting a value contained between the peak strain for compression and the peak strain for extension, according to the observations reported by Karlsrud and Hernandez-Martinez (2013) for Norwegian clays. Strainsoftening is clearly visible for compression behavior and occurs after a peak shear strain of about $2 \%$ (brittle behavior), while for extension no clear peak is reached before $8-10 \%$ of strain. A residual strength level of about $50 \%$ of the peak in compression is reached at a shear strain level of $25 \%$. The more sensitive layer is modelled simply assuming a lower strength at large strain (about $40 \%$ of the peak at $25 \%$ of shear strain), as shown in Fig. 15.

The NGI-ADPSoft model is able to reproduce rather well both CAUC and CAUE tests. According to the authors' experience, for Finnish sensitive clays the $86 \mathrm{~mm}$ sampler used tends to assure a better sample quality than the $54 \mathrm{~mm}$ piston sampler. However, the tested specimens may have been subjected to some disturbance effects caused by sampling, transportation and trimming procedures. Sample disturbance can notably affect the stress-strain response of soft clays. According to Lunne et al. (1997), sample disturbance provokes a reduction in the peak strength, an increase in the shear strain at failure and a higher shear stress at large strain.

Input parameters for NGI-ADPSoft model are shown in Table 4. Values for $\mathrm{G}_{0} / \mathrm{s}_{\mathrm{u}}{ }^{\mathrm{A}}$ are chosen according to Karlsrud and Hernandez-Martinez (2013). Reasonable soil parameters are chosen for the varved silty clay, based on the authors' experience, by assuming the same anisotropic behavior of the soft Perniö clay. For the clay layers below the embankment, $y_{\text {ref }}$ varies according to a gradient $\left(\Delta \mathrm{y}_{\mathrm{ref}} / \Delta \mathrm{x}\right)$, in order to keep $\mathrm{s}_{\mathrm{u}}=\mathrm{s}_{\mathrm{u}}{ }^{\mathrm{A}}$ ref at any point of the top part of the layers. The lateral stress coefficient $\left(K_{0}\right)$ is calculated according to Kulhawy and Mayne (1990) [eq. (16)]. 


$$
K_{0}=\left(1-\sin \phi^{\prime}\right) O C R^{\sin \phi^{\prime}}
$$

\section{Dry crust}

Clay deposits often contain a surface crust of weathered and fissured clay. Usually, the properties of these clays are affected because of phenomena of oxidation, desiccation, freezing-thawing or fluctuation of water table.

Part of the slip surface generally goes through the dry crust. Therefore, for an accurate prediction of the failure load it would seem important, in the authors' opinion, to reliably estimate the potential available strength in this layer. However, it is quite challenging to take undisturbed samples of the dry crust because of its non-homogeneous structure, often characterized by the presence of cracks (D’lgnazio 2016).

The FV test shows uncorrected $\mathrm{s}_{\mathrm{u}}$ values well over $50 \mathrm{kPa}$ (Lehtonen 2011, Fig. 3). It has been shown by some authors (Lo 1970, La Rochelle et al. 1974, Lefebvre et al. 1987, Khan 1993, D'lgnazio et al. 2015; D'Ignazio 2016) how the FV tends to overestimate $s_{u}$ when the clay presents fissures. The presence of fissures in the layer will cause the strength measured on a small scale (field vane) to be larger than on a large scale (e.g. a failure surface) (La Rochelle et al. 1974).

14 isotropically consolidated triaxial compression (CIUC) unsaturated tests were done on $15 \mathrm{~cm}$ size block samples of Perniö dry crust, taken about $50 \mathrm{~m}$ off the test location. An extensive description of the tests performed to characterize the Perniö dry crust is presented by D'Ignazio (2016). The average measured TXC undrained strength at the top was $35 \mathrm{kPa}$ decreasing with depth towards the soft clay, which is lower than the strength measured by the $\mathrm{FV}\left(\mathrm{s}_{\mathrm{u}}>50 \mathrm{kPa}\right)$.

As discussed by D'Ignazio et al. (2015) and D'Ignazio (2016), the dry crust layer in Perniö was originally about $1.5 \mathrm{~m}$ thick, while in the experiment and, therefore, in the FE model presented in this paper, it was roughly $1 \mathrm{~m}$ thick. A reason might be that the upper part of the clay crust was removed before the construction of the sand fill layer, several years before the experiment took place. Characteristics of Perniö dry crust are reported in Tab. 3. From the test results, the upper part of the layer (above $1.0 \mathrm{~m}$ ) seems partially saturated, while the lower part is fully saturated. This might be the result of the seasonal fluctuations of the groundwater table. However, in this 
study the clay crust is modelled with a total stress soil model (NGI-ADP); therefore, partial saturation will not constitute an issue, as suction is implicitly included in the $\mathrm{s}_{\mathrm{u}}$.

As discussed by D'Ignazio et al. (2015), the adoption of different soil models for the dry crust does not influence the global response of the FE analysis of Perniö failure test, as it seems that the ground response was mainly governed by the soft clay layers.

Input parameters for the clay units used in the model are reported in Tab. 4 and the undrained shear strength profile for Perniö is shown in Fig. 16.

\section{Coarse layers}

The embankment made of crushed ballast, the sand fill and the lower sandy layer are modelled as hardening isotropic materials using the Hardening Soil model (Schanz et al. 1999) implemented in PLAXIS.

Stiffness and strength parameters have been estimated according to the Finnish Road Design Manual (Tiehallinto 2001) and to Mansikkamäki (2015). $E_{\text {oed }}{ }^{\text {ref }}$ was chosen equal to $E_{50}$ ref, while $E_{u r}{ }^{\text {ref }}=3^{\star} E_{50}{ }^{\text {ref }}$, as suggested by the user's manual of Plaxis (Plaxis 2012). Effective friction angle $\left(\phi^{\prime}\right)$ and dilatancy angle $(\psi)$ are chosen according to Mansikkamäki (2015). Input parameters for the Hardening Soil model are reported in Table 5.

\section{FINITE ELEMENT ANALYSIS}

The A-A (middle) cross section (Fig. 2) was chosen for the FE 2D analysis, being probably the most representative of plane-strain conditions.

The finite element mesh for the plane-strain analysis of the A-A cross section consisted of 3432 15-noded triangular elements with average element size of $0.32 \mathrm{~m}$ and it is presented in Fig. 17. The global coarseness was set to "very fine", with cluster refinement in the soft clay layers.

The boundary conditions applied to the FE model are such that the bottom boundary was fully fixed, so that no movements were allowed both in the horizontal and the vertical direction. Roller 
conditions were applied at the two vertical sides, meaning that movements in the horizontal direction were not permitted.

The adopted construction sequence was the same as that on site, assuming fully undrained conditions. Firstly, initial stress conditions were generated through a " $\mathrm{K}_{0}$ " procedure, assuming the layers as horizontal, even though a gentle inclination is visible (results are not affected by the stress generation procedure). Secondly, the ditch was excavated and the embankment built, before the whole load-to-failure process.

The applied load was simulated using a rigid block (linear elastic material) one $m$ high on top of the embankment with given unit weight, according to the load step phase. A rigid load would describe the loading over rails and the effect of the concrete sleepers, present in the experiment. In order to determine the failure load, an incremental multiplier procedure was adopted: a distributed load was placed on top of the rigid block with given unit weight of $1 \mathrm{kN} / \mathrm{m}^{3}$, and incremented by $1 \mathrm{kPa}$ loading steps, until peak capacity occurs. In order to model the failure mechanism, the incremental multiplier analysis was further continued after peak until the vertical displacement of the embankment was approximately equal to $1 \mathrm{~m}$ (measured after the containers tipped over) at point A (Fig. 17).

The load-time-settlement behavior was modelled in three phases. In the first phase, a rigid load of $24 \mathrm{kPa}$ was applied and, in a second phase, kept constant, to simulate the interruption of the loading process during night. In the third phase, a load equal to the failure load calculated from the incremental multipliers procedure was applied. The effect of the more sensitive clay layer on the failure mechanism was studied through two separate analyses. Firstly, the residual strength of the sensitive clay layer at large strain was set equal to the residual strength of the soft clay $(50 \%$ of the peak compression strength), and secondly it was reduced by $20 \%$ ( $40 \%$ of the peak compression strength), as shown in Fig. 15. 


\section{Failure load}

The computed peak failure load from the FE analysis using incremental multipliers $\left(\mathrm{q}_{\mathrm{soft}}\right)$ is 80.8 $\mathrm{kPa}$. According to the work done by Mansikkamäki (2015), the duration of loading process in the Perniö failure test has a significant impact on the bearing capacity, as a direct consequence of the rate dependency of $s_{u}$. If the embankment were loaded slowly enough, the failure load would have been lower than the measured $87 \mathrm{kPa}\left(\mathrm{q}_{\mathrm{test}}\right)$ (Mansikkamäki et al. 2011; Mansikkamäki 2015).

3D analyses of Perniö failure test have shown that the 3D failure load might be 5-12 \% higher than in plane strain (Mansikkamäki and Länsivaara 2012; Mansikkamäki 2015). Therefore, the calculated value of $\mathrm{q}_{\text {soft }}=80.8 \mathrm{kPa}$ seems like a fairly good estimate considering (i) that rate as well as $3 \mathrm{D}$ effects are not taken into account and (ii) the uncertainties in the input parameters (e.g. the spatial distribution of the actual shear strengths).

The effect of strain-softening on the failure capacity is evaluated through an equivalent analysis where residual shear strengths are set equal to their respective peak strength in the three directions of loading (anisotropic elasto-plastic analysis). The resulting failure load in the equivalent analysis is $6.2 \%$ higher than when strain-softening is modelled.

Moreover, the impact of anisotropy on the ultimate capacity is examined by assuming an average isotropic $\mathrm{s}_{u}$ of the clay equal to $\mathrm{s}_{u}{ }^{\text {avg }}=\left(\mathrm{s}_{\mathrm{u}}{ }^{\mathrm{A}}+\mathrm{s}_{\mathrm{u}}{ }^{\text {DSS }}+\mathrm{s}_{\mathrm{u}}{ }^{\mathrm{P}}\right) / 3$. In this case, the failure load is $8.9 \%$ higher (88 $\mathrm{kPa}$ versus $80.8 \mathrm{kPa})$.

When using $\mathrm{S}_{\mathrm{u}}{ }^{\text {avg }}=\mathrm{s}_{\mathrm{u}}{ }^{\text {DSS }}$ the calculated capacity does not significantly differ from the ADP analysis with softening $(0.4 \%$ less $)$. However, for $\mathrm{s}_{\mathrm{u}}{ }^{\text {avg }}$ equal to the average measured $\mathrm{FV}$ strength $\left(\mathrm{S}_{\mathrm{u}}{ }^{\mathrm{FV}}\right.$, corrected values), the capacity of the Perniö embankment is underestimated by $8.5 \%$. The computed failure load for different scenarios and the input parameters that differ from those of Table 4 are summarized in Table 6 . Input shear strains were maintained equal to their initial values reported in Table 4, as the focus was on the failure load, which is a function of the input $\mathrm{s}_{\mathrm{u}}$. 


\section{Failure mechanism}

The failure mechanism was studied through two separate analyses, where the soft clay layer was firstly modelled as one single layer, and secondly divided into two layers with different post-peak behavior. When comparing the approximate failure surface from the failure test to the computed shear zone, they seem to share the same starting and ending points, even though the location differs slightly in the active side below the embankment. In Fig. 18 the modelled shear bands at failure predicted by the incremental deviatoric strain $\left(\Delta \gamma_{s}\right)$ and the observed shear band (see Figure 5) are illustrated. The computed shear zones correspond to a strain level that is reached when the vertical displacement of the embankment is about $1 \mathrm{~m}$ (maximum displacement measured in the experiment after the containers fell on their side). The failure mechanism interpreted from the test seems deeper than the one modelled by the FE analysis, when the more sensitive clay layer is not modelled. When the deep sensitive layer is included in the calculation, the failure mechanism is forced down to a greater depth, which is in better agreement with field observations (Fig. 18). While the approximate failure surface appears to steeply reach the top of the stiffer silty clay layer, the modelled surface bends up more smoothly towards the ditch. The modelled shear zone reaches its maximum depth at a point which has approximately $5 \mathrm{~m}$ horizontal distance from the center line of the embankment. According to field data, the maximum depth was reached at point only 3.0 to $3.5 \mathrm{~m}$ from the centre-line (Fig. 5 and Fig. 18). The peak failure load is not affected by the two different model scenarios with different failure mechanisms.

\section{Displacements}

Fig. 19 shows the load-settlement-time curve for point $A$ for the scenario described by the soil parameters of Table 4, which includes the sensitive soil layer with modified post-peak properties (see Fig. 15). Vertical displacements from the FE analysis are compared with settlement recorded by settlement transducer 53 (located as shown in Fig. 4). Failure occurred in the experiment right after a vertical displacement of about $0.11 \mathrm{~m}$ measured from the top of the embankment was reached. 
Although creep is neglected, pre-failure settlement can be predicted reasonably well (Fig. 19), even though the results seem slightly overestimated after the onset of first yielding (about 3.5 hours before failure). On the other hand, vertical displacement right before failure is modelled quite accurately.

Horizontal movements during the loading process were recorded in the foundation soil by nine individual inclinometers located in three sections at the toe of the embankment, at the middle and edge of the ditch. Three tubes were placed in each section.

The inclinometer tubes are numbered one to three from the embankment towards the ditch. The solid lines in Fig. 20 show the predicted horizontal displacements $\left(u_{x}\right)$ versus elevation at the toe of the embankment, at the middle and edge of the excavated ditch from inclinometers L2P1, L2P2 and L2P3, respectively.

Calculated horizontal displacements are compared (Fig. 20) with the measured displacements during loading and before failure, recorded at 21:25. Observed displacements correspond to given applied loads (q) of $68.5,78.5$ and $87 \mathrm{kPa}$ (last loading step at 19:30). Given loads of $68.5 \mathrm{kPa}$ and $78.5 \mathrm{kPa}$ correspond to $78 \%$ and $90 \%$ of the measured failure load in the test ( $\left.\mathrm{q}_{\mathrm{test}}=87 \mathrm{kPa}\right)$. As the computed failure load $\left(q_{\text {soft }}=80.8 \mathrm{kPa}\right)$ is lower than $q_{\text {test }}$, field measurements are compared to displacements caused by loads corresponding to $78 \%, 90 \%, 99 \%$ and $100 \%$ of $\mathrm{q}_{\text {soft }}$.

Measured horizontal movements are generally smaller than those predicted by NGI-ADPSoft model, except for the last readings before failure from inclinometer L2P1 and L2P2, where the maximum horizontal displacement $\left(u_{x}{ }^{\max }\right)$ is predicted with relatively low error. One possible reason could be that the peak shear strains used in the calculation are higher than those in situ, as a consequence of disturbed sampling.

However, it is quite challenging to accurately model the variation of horizontal movements with depth right before failure, especially in the lower layers at elevation of 2-3 $\mathrm{m}$. One possible reason is that the computed shear band at peak occurs at higher elevation (as if the more sensitive layer was not modelled, see Fig. 18) than in the real experiment (Fig. 5). In contrast, at smaller strains the lateral displacement profiles can be reproduced fairly well, even though the computed values are higher than field measurements (Fig. 20). 


\section{Effect of strain softening and development of progressive failure}

Fig 21 and Fig. 22 show the contours of hardening parameters $\kappa_{1}$ and $\kappa_{2}$, respectively, corresponding to different embankment settlements. $\kappa_{2}$ becomes greater than zero when the mobilized stress overcomes the peak strength; while it is equal to one when the residual strength is fully mobilized. The pre-peak hardening control parameter $\kappa_{1}$ becomes equal to one when the peak strength is reached.

For a perfectly plastic material, failure occurs when all the material points along a critical failure surface have reached the maximum shear stress. On the contrary, with NGI-ADPSoft model the unstable condition (failure) is locally achieved when the shear stress over some length along the shear band has passed the peak shear strength. When the peak failure capacity $\left(q_{\text {soft }}\right)$ is reached for an embankment settlement of about $0.11 \mathrm{~m}, \kappa_{1}$ is equal to one at some locations and lower than one in the surrounding soil (Fig. 21a), where the mobilized shear strength is still below the peak strength. At the same time, $\kappa_{2}>0$ indicates that peak strengths have been passed at some points in the subsoil (Fig. 22a). By increasing the deformation at this state further, the resistance in the post-peak (softening) zone will reduce more than the increase in the pre-peak (hardening) zone. The calculated global resistance will therefore be reduced after this state. For an embankment settlement of about $1 \mathrm{~m}$ (Fig. 21b and 22b), the peak state is reached (Fig. 21b) and passed (Fig. 22b) at some other locations in the subsoil. As further shown by Fig. 22b, the residual state is attained in the clay layers where $\kappa_{2}=1$.

\section{Sensitivity analysis}

Difficulties were encountered in the derivation of $S_{u}$ for DSS type of loading from the comparison between FV test results and some existing correlations. When $\mathrm{s}_{\mathrm{u}}{ }^{\mathrm{DSS}} / \mathrm{s}_{\mathrm{u}}{ }^{\mathrm{A}}$ is set equal to 0.70 , the resulting failure load is $5 \%$ higher than for $\mathrm{S}_{u}{ }^{D S S} / \mathrm{s}_{u}{ }^{A}=0.65$; while when it is set equal to 0.75 , the embankment can sustain a load of $88.10 \mathrm{kPa}$ ( $9 \%$ higher), which seems to be a quite high load without accounting neither for rate effect nor for 3D geometry. 
On the other hand, uncertainty in $\mathrm{S}_{\mathrm{u}}{ }^{\mathrm{P}}$ is less important to the global behavior of the Perniö embankment, since the failure load becomes only $4 \%$ lower by reducing $\mathrm{s}_{u}{ }^{\mathrm{P}} / \mathrm{s}_{\mathrm{u}}{ }^{\mathrm{A}}$ by $20 \%$ to 0.4 . The measured $\mathrm{s}_{\mathrm{u}}{ }^{\mathrm{P}} / \mathrm{s}_{\mathrm{u}}{ }^{\mathrm{A}}$ may be, however, affected by sample disturbance. According to the study carried out by Karlsrud and Hernandez-Martinez (2013) on block samples of Norwegian soft clays, for undrained TXC tests the sample disturbance affects peak strengths by $10-50 \%$, while in extension tests sample disturbance affects the peak strength by $0-10 \%$.

By running a FE analysis dividing the peak shear strains in the three directions of loading by a factor of 2, nearly no influence on the peak capacity is observed (less than $2 \%$ ); however, a higher impact is observed with regard to displacements, as the maximum computed horizontal displacement is reduced by $35 \%$ (Fig. 23).

When $\mathrm{l}_{\text {int }}$ is reduced from $0.4 \mathrm{~m}$ to $0.1 \mathrm{~m}$, a failure load $5 \%$ lower is calculated; while when $\mathrm{I}_{\text {int }}=0.7$ $\mathrm{m}$, a higher load (about $4 \%$ ) is needed to reach failure.

The number of elements constituting the mesh has a small effect on the ultimate capacity, demonstrating how the non-local strain formulation implemented in NGI-ADPSoft model truly avoids mesh dependency. By refining the mesh clusters in the soft clay layers and thus increasing the element number from 1203 to 1956 and 3432, the difference in the failure load is less than $3 \%$. Both horizontal and vertical displacements have not shown any pertinent change with different element sizes.

The failure mechanism is also not linked to the number of elements of the FE discretization. Although $\mathrm{l}_{\text {int, }}$, and consequently $\mathrm{t}_{\mathrm{sb}}$, were varied, the calculated shear zone reaches the same elevation for all the analyzed configurations.

An increase of about $6 \%$ in the failure load is obtained by varying the softening parameters $\mathrm{c}_{1}$ and $\mathrm{C}_{2}\left(\mathrm{c}_{1}=\mathrm{C}_{2}\right)$ from 1 (from fitting to CAUC tests) to 2 . This is an expected result, since the post-peak response would provide "less" strain-softening immediately after the peak state, thus influencing the peak capacity.

The coarse layers do not significantly influence the stability of the Perniö embankment. Small variations in stiffness or in the friction angle do not lead to any remarkable differences. However, the $s_{u}$ of the dry crust seems to notably affect the FE calculation results. When using a constant 
input $\mathrm{s}_{\mathrm{u}}=40 \mathrm{kPa}$ based on FV test results (according to Lehtonen 2011), the computed failure load is $94 \mathrm{kPa}$. This would confirm how FV test in weathered clays provides unreliable measurements, in agreement with the findings of Lo (1970), La Rochelle et al. (1974), Lefebvre et al. (1987), Khan (1993) and D'Ignazio et al. (2015).

\section{DISCUSSION}

The calculated failure load from the advanced FE analysis presented in this study $(80.8 \mathrm{kPa})$ is $7.1 \%$ lower than the observed failure load in the experiment $(87 \mathrm{kPa})$. The discrepancy in the results might be attributed to $3 \mathrm{D}$ effects or time/rate effects, which are not modelled in this study. As discussed by Mansikkamäki (2015), the FE 3D modelled failure load for simulations of the Perniö test can be 5 to $12 \%$ higher than in a $2 \mathrm{D}$ plane-strain analysis.

Partial drainage of excess pore pressure, which could also explain the high measured bearing pressure and, therefore, justify the erroneously predicted failure load in the FE calculation, may have occurred only over a very thin zone adjacent to one of the more permeable boundaries (Lehtonen et al. 2015). Measured excess pore water pressure before failure did not show any reduction (Fig. 6), thus reducing the credibility of the hypothesis of migration of the pore water. Failure must have occurred under nearly fully undrained conditions because of the short duration of the load-to-failure process and the low permeability of the soft clay layer (Lehtonen et al. 2015). Correlating strain rates occurring in the field with those from laboratory tests is quite challenging, as in the field the rate of strain comes from a load-controlled process, while conventional laboratory tests are performed at constant rate of strain.

Conventional triaxial undrained tests in Finland are performed at axial strain rate of about $1 \% / \mathrm{h}$, meaning that the soil sample will reach the failure state within a few hours. On the contrary, undrained failure in the field may also occur in several days, as discussed by e.g. La Rochelle et al. (1974). According to the study presented in this paper, $s_{u}$ from TXC/TXE can fairly well represent a situation where the load is applied quickly, as in the Perniö failure test. Therefore, attention must be paid when triaxial strength is used for stability or bearing capacity calculation, as 
it might lead to an overestimation of the safety level when the load is applied over a longer period of time than in the Perniö test. For instance, a critical case could be when the loading process is performed at a much lower strain rate (e.g. tenfold) than in a standard triaxial test (which is in most of the cases), from where the strength parameters are determined. In that case, $s_{u}$ needs to be reduced because of rate effects, to be representative of the loading conditions and to provide a reasonable estimate of the failure load.

The effect of strain rate on the inferred $\sigma_{p}^{\prime}$ of soft Finnish clays, and therefore also on the $s_{u}$, is described by Länsivaara $(1995,1999,2012)$ and summarized by eq. (17):

$$
\frac{\sigma_{p 2}^{\prime}}{\sigma_{p 1}^{\prime}}=\left(\frac{\dot{\varepsilon}_{2}}{\dot{\varepsilon}_{1}}\right)^{B}
$$

Where $\sigma_{p 2}^{\prime}$ and $\sigma_{p 1}^{\prime}$ are the values of interpreted $\sigma_{p}^{\prime}$ from CRS oedometer tests performed at strain rates $\dot{\varepsilon}_{2}$ and $\dot{\varepsilon}_{1}$, respectively. Their dependency was found to be a function of the ratio between the creep index and the compression index of the soil $\left(B=C_{\alpha} / C_{c}\right)$. For Finnish soft clays $B=0.068$ 0.079 (Länsivaara 1995, 1999, 2012). For instance, for $B=0.068-0.079$ and $\dot{\varepsilon}_{2} / \dot{\varepsilon}_{1}=0.1, \sigma_{\mathrm{p}}^{\prime}$ is reduced by $17-20 \%$. By applying the same reduction to $\mathrm{s}_{\mathrm{u}}$, the failure load in the Perniö failure test would be lower than $75 \mathrm{kPa}$ (e.g. stress path A-B of Fig. 7).

\section{CONCLUSIONS}

This study has presented the finite element analysis of a shallow railway embankment built on a soft sensitive clay deposit in Perniö, Western Finland. The failure test analyzed was part of a joint research program between Tampere University of Technology and the Finnish Transport Agency. A series of conclusions can be drawn from this study:

1. From the elaboration of inclinometers readings, it was demonstrated how the rate of shear strain in the full-scale test increased during loading, even while the load was kept constant before failure. This would suggest that failure in the Perniö failure experiment was caused 
by undrained creep phenomena in the soft clay, thus supporting the conclusions drawn by Lehtonen et al. (2015) based on pore pressure measurements.

2. NGI-ADPSoft soil model can appropriately reproduce the behavior of anisotropic saturated soft sensitive clays, which exhibit post peak strain-softening behavior, provided that model parameters are derived carefully and reasonable values for the non-local strain used to regularize the problem are chosen.

3. The predicted failure load of $80.8 \mathrm{kPa}$, based on the best estimate of soil properties, versus the $87 \mathrm{kPa}$ measured, represents a very good result considering that rate and $3 \mathrm{D}$ effects are not taken into account.

4. Undrained shear strength from triaxial tests performed at standard strain rate seems to be representative of the "fast" loading conditions at the failure test. For slower loading or for longer load duration, it would seem necessary to reduce the undrained shear strength from triaxial tests with respect to strain rate.

5. The failure load is not found to be remarkably dependent on either mesh size or thickness of the shear band, since either varying mesh size or internal length, the variation falls into a narrow range of $\pm 5 \%$.

6. The anisotropy ratio assumed for DSS $\left(\mathrm{S}_{\mathrm{u}}{ }^{\mathrm{DSS}} / \mathrm{S}_{\mathrm{u}}{ }^{\mathrm{A}}\right)$ seems to have a pronounced impact on the predicted failure load, while the anisotropy ratio for extension $\left(\mathrm{s}_{u}{ }^{\mathrm{P}} / \mathrm{s}_{\mathrm{u}}{ }^{\mathrm{A}}\right)$ had a minor effect on the FE results. This may be due to the shape of the failure surface.

7. Pre-failure vertical settlement of the embankment was modelled quite accurately. The calculated pre-failure horizontal displacements followed the observed trends, even though the magnitude of calculated displacement did not exactly match the observations.

8. The interpreted failure mechanism in the full-scale test seems deeper than the shear zone predicted by the plane-strain analysis. Moreover, the shear band from the FE study reaches its maximum depth at a slightly different coordinate then in the failure test. Nevertheless, the failure zone is properly reproduced when a more sensitive layer is modelled on top of the stiff silty clay layer. By slightly changing the post-peak properties of this layer (i.e. $20 \%$ lower residual strength), more plastic strains will develop in the post 
peak regime for a given strain level, thus dragging the failure mechanism deeper down. The triggering peak failure load will remain substantially the same.

\section{ACKNOWLEDGEMENTS}

The authors acknowledge the Finnish Transport Agency for funding this research project. A special thank is also given to Dr. Khoa D.V. Huynh from the Norwegian Geotechnical Institute for the technical support with the NGI-ADPSoft model. Dr. Marco D'Ignazio sincerely thanks Dr. Ville Lehtonen and Dr. Juho Mansikkamäki, from the Tampere University of Technology, for the valuable suggestions made to enrich the work presented in this article. Finally, the Authors would like to thank the reviewers, and in particular the Editor, for their useful and helpful comments on the manuscript. 


\section{References}

Andresen, L., Jostad, H.P., and Høeg, K. 2002. Numerical procedure for assessing the capacity of anisotropic and strain-softening clay. In Proceedings of the 5th World Congress on Computational Mechanics, WCM V, Wien, Austria.

Andresen, L., Saygili, G., and Grimstad, G. 2011. Finite Element analysis of the Saint-Alban embankment failure with an anisotropic undrained strength model. In Proceedings of the $15^{\text {th }}$ European Conference of Soil Mechanics and Geotechnical Engineering. Athens, Greece. pp. 1111-1118.

Arulanandan, K., Shen, C., and Young, R. 1971. Undrained creep behaviour of a coastal organic silty clay. Géotechnique, 21(4): 359-375.

Bazant, Z. P. 1976. Instability, ductility, and size effect in strain-softening concrete. Journal of the Engineering Mechanics Division, 102(2): 331-344.

Bernander, S. 2000. Progressive landslides in long natural slopes. Formation, potential extension and configuration of finished slides in strain-softening soils. Licentiate thesis, Luleå University of Technology.

Berre, T. 1969. Studies of yield stress and time effect in the Drammen clay. In Bolkesji symposium on shear strength and consolidation of normally consolidated clays (papers). pp. 31-36.

Berre, T., and Bjerrum, L. 1973. Shear strength of normally consolidated clays. In Proceedings of the 8th International Conference on Soil Mechanics and Foundation Engineering, Moscow. Vol. 1.1 , pp. 39-49. 
Bishop, A.W. 1967. Progressive failure with special reference to the mechanism causing it. In Proceedings of Geotechnical Conference, September 1961, Oslo. Vol. 2, pp. 142-150.

Bishop, A. W. 1971. The influence of progressive failure on the choice of the method of stability analysis. Geotechnique, 21(2): 168-172.

Bjerrum, L. 1967. Engineering geology of Norwegian normally consolidated marine clays as related to settlements of buildings. 7th Rankine lecture. Géotechnique, 17(2): 81-117.

Bjerrum, L. 1972. Embankments on soft ground. In Proceedings of the ASCE Specialty Conference on Performance of Earth and Earth-Supported Structures, Purdue University, Lafayette, Ind. ASCE. Vol. 2, pp. 1-54.

Bjerrum, L. 1973. Problems of Soil Mechanics and Construction on Soft Clays. State-of-the-art report. In Proceedings, 8th ICSMFE, Moscow. Vol. 3, pp. 111-159.

Bjerrum, L., and Landva, A. 1966. Direct simple-shear tests on a Norwegian quick clay. Géotechnique, 16(1): 1-20.

Brinkgreve, R.B.J. 1994. Geomaterial models and numerical analysis of softening. PhD thesis, TU Delft, Delft University of Technology.

Chandler, R.J. 1988. The in-situ measurement of the undrained shear strength of clays using the field vane. In Vane shear strength testing in soils: field and laboratory studies. ASTM STP 1014. ASTM, Philadelphia, Pa. pp. 13-44.

Ching, J., and Phoon, K.-K. 2012. Establishment of generic transformations for geotechnical 
design parameters. Structural Safety, 35: 52-62. doi:10.1016/j.strusafe.2011.12.003.

Ching, J., Phoon, K.-K., and Lee, W.T. 2013. Second-moment characterization of undrained shear strengths from different test procedures. In Proceedings, Foundation Engineering in the Face of Uncertainty: Honoring Professor F.H. Kulhawy. Geotechnical Special Publication 229. ASCE, Reston, Va. pp. 308-320.

De Borst, R., Sluys, L.J., Muhlhaus, H.B., and Pamin, J. 1993. Fundamental issues in finite element analyses of localization of deformation. Engineering computations, 10(2): 99-121.

D'lgnazio, M. 2016. Undrained shear strength of Finnish clays for stability analyses of embankments. PhD thesis, Tampere University of Technology, Tampere.

D'lgnazio, M., and Länsivaara, T. 2015. Shear bands in soft clays: strain-softening behavior in finite element Method. Rakenteiden Mekaniikka (Journal of Structural Mechanics), 48(1): 83-98.

D’Ignazio, M., Mansikkamäki, J., and Länsivaara, T. 2014. Anisotropic total and effective stress stability analysis of the Perniö failure test. In Proceedings of Conference on Numerical Methods in Geotechnical Engineering (NUMGE), Delft, Netherlands. Vol. 2, pp. 609-614.

D'Ignazio, M., Di Buò, B., and Länsivaara, T. 2015. A study on the behavior of weathered clay crust in the Perniö failure test. In Proceedings of XVI ECSMGE, 13-17 September 2015, Edinburgh, Scotland. Vol. 7, pp. 3639-3644.

D'Ignazio, M., Phoon, K.K., Tan, S.A., and Länsivaara, T. 2016. Correlations for undrained shear strength of Finnish soft clays. Canadian Geotechnical Journal, 53(10): 1628-1645. 
Desrues, J., and Viggiani, G. 2004. Strain localization in sand: an overview of the experimental results obtained in Grenoble using stereophotogrammetry. International Journal for Numerical and Analytical Methods in Geomechanics, 28(4): 279-321.

Eringen, A.C. 1981. On nonlocal plasticity. International Journal of Engineering Science, 19(12): $1461-1474$.

Graham, J., Crooks, J., and Bell, A. 1983. Time effects on the stress-strain behaviour of natural soft clays. Géotechnique, 33(3): 327-340.

Grimstad, G., Andresen, L., and Jostad, H.P. 2012. NGI-ADP: Anisotropic shear strength model for clay. International Journal for Numerical and Analytical Methods in Geomechanics 36(4): 483-497.

Grimstad, G., Jostad, H.P., and Andresen, L. 2010. Undrained capacity analyses of sensitive clays using the nonlocal strain approach. In Proceedings of the 9th HSTAM International Congress on Mechanics, Vardoulakis mini-symposia, Limassol, Kypros, 12-14 July. pp. 153-160.

Gylland, A.S. 2012. Material and slope failure in sensitive clays. PhD thesis, Norwegian University of Science and Technology (NTNU), Trondheim.

Hicher, P.Y., Wahyudi, H., and Tessier, D. 2000. Microstructural analysis of inherent and induced anisotropy in clay. Mechanics of Cohesive-frictional Materials, 5(5): 341-371.

Holzer, T.L., Höeg, K., and Arulanandan, K. 1973. Excess pore pressures during undrained clay creep. Canadian Geotechnical Journal, 10(1): 12-24.

Jamiolkowski, M., Ladd, C.C., Germain, J.T., and Lancellotta, R. 1985. New developments in field and laboratory testing of soils. In Proceedings of the 11th International Conference on Soil 
Mechanics and Foundation Engineering, San Francisco. Vol. 1, pp. 57-153.

Janbu, N. 1985. Soil models in offshore engineering. Géotechnique, 35(3): 241-281.

Jostad, H. P., and Andresen, L. 2004. Modeling of shear band propagation in clays using interface elements with finite thickness. In Proceedings of International Symposium on Numerical Models in Geomechanics, 25-27 August 2004, Ottawa, Canada. Vol. 9, pp. 121-128.

Jostad, H.P., and Grimstad, G. 2011. Comparison of distribution functions for the nonlocal strain approach. In Proceedings, 2nd International Symposium on Computational Geomechanics, CavtatDubrovnik, Croatia. pp. 212-223.

Jostad, H.P., Andresen, L., and Thakur, V. 2006. Calculation of shear band thickness in sensitive clays. In Proceedings, 6th European Conference on Numerical Methods in Geotechnical Engineering Graz, Austria. pp. 27-32.

Jostad, H.P., Fornes, P., and Thakur, V. 2014. Effect of Strain-Softening in Design of Fills on Gently Inclined Areas with Soft Sensitive Clays. In Landslides in Sensitive Clays. Edited by Springer Netherlands. pp 305-316.

Karlsrud, K., Lunne, T., Kort, D.A., and Strandvik, S. 2005. CPTU correlations for clays. In Proceedings of the XVIth International Conference on Soil Mechanics and Geotechnical Engineering, ICSMGE, Osaka, Japan. Vol. 2, pp. 693-702.

Karlsrud, K., and Hernandez-Martinez, F.G. 2013. Strength and deformation properties of Norwegian clays from laboratory tests on high-quality block samples 1. Canadian Geotechnical Journal, 50(12):1273-1293. 
Karlsrud, K., Aas, G., and Gregersen, O. 1984. Can we predict landslide hazards in soft sensitive clays? Summary of Norwegian practice and experiences. In Proceedings of the 4th International Symposium on Landslides, Toronto, Ont., 16-21 September 1984. University of Toronto Press, Toronto, Ont. Vol. 1, pp. 107-130.

Karstunen, M., Krenn, H., Wheeler, S.J., Koskinen, M., and Zentar, R. 2005. Effect of anisotropy and destructuration on the behavior of Murro test embankment. International Journal of Geomechanics, 5(2): 87-97.

Khan, M.A. 1993. Strength-deformation behavior of a weathered clay crust. PhD thesis, Department of Civil Engineering, University of Ottawa, Canada.

Kolisoja, P., Sahi, K. and Hartikainen, J. 1989. An automatic triaxial-oedometer device. In Proceedings of the 12th International Conference on Soil Mechanics and Foundation Engineering, Rio de Janeiro. 1: 61-64.

Koskinen, M. 2014. Plastic anisotropy and destructuration of soft Finnish clays. PhD thesis, Aalto University. Helsinki.

Kulhawy, F.H., and Mayne, P.W. 1990. Manual on estimating soil properties for foundation design (No. EPRI-EL-6800). Electric Power Research Inst., Palo Alto, CA (USA); Cornell Univ., Ithaca, NY (USA). Geotechnical Engineering Group.

La Rochelle, P., Trak, B., Tavenas, F., and Roy, M. 1974. Failure of a test embankment on a sensitive Champlain clay deposit. Canadian Geotechnical Journal, 11(1): 142-164. doi:10.1139/t74-009. 
Ladd, C.C. 1977. Stress-deformation and strength characteristics, state of the art report. In Proceedings of the 9th ISFMFE. Vol. 4, pp. 421-494.

Ladd, C.C. 1991. Stability evaluation during staged construction. (22 ${ }^{\text {nd }}$ Terzaghi Lecture.) Journal of Geotechnical Engineering, 117(4): 540-615.

Ladd, C.C., and Foott, R. 1974. New design procedure for stability of soft clays. Journal of the Geotechnical Engineering Division, ASCE, 100(7): 763-786.

Länsivaara, T. 1995. A critical state model for anisotropic soft soils. In Proceedings of the 11th European Conference of Soil Mechanics and Foundation Engineering, Copenhagen, Denmark. Vol. 6. pp. 101-106.

Länsivaara, T. 1999. A study of the mechanical behavior of soft clay. PhD thesis, Norwegian University of Science and Technology, Trondheim.

Länsivaara, T. 2012. Some aspects on creep and primary deformation properties of soft sensitive Scandinavian clays. In Proceedings of the $16^{\text {th }}$ Nordic geotechnical meeting, NGM, 9-12 May 2012, Copenhagen, Denmark. pp. 397-404.

Länsivaara, T., Lehtonen, V., and Mansikkamäki, J. 2011. Failure induced pore pressure, experimental results and analysis. In Proceedings of Pan-Am CGS Geotechnical conference, Toronto.

Länsivaara, T., Mansikkamäki, J., and Lehtonen, V. 2014. Effective stress based stability analysis on normally consolidated clays. In Landslides in Sensitive Clays. Edited by Springer Netherlands. pp. 317-328. 
Larsson, R. 1980. Undrained shear strength in stability calculation of embankments and foundations on soft clays. Canadian Geotechnical Journal, 17(4): 591-602.

Larsson, R., Sällfors, G., Bengtsson, P.E., Alén, C., Bergdahl, U., and Eriksson, L. 2007. Skjuvhällfasthet: utvärdering I kohesionsjord ( $2^{\text {nd }}$ edition), Information 3. Swedish Geotechnical Institute (SGI), Linköping.

Lefebvre, G., and LeBoeuf, D. 1987. Rate effects and cyclic loading of sensitive clays. Journal of Geotechnical Engineering, 113(5): 476-489.

Lefebvre, G., Paré, J.J., and Dascal, O. 1987. Undrained shear strength in the surficial weathered crust. Canadian Geotechnical Journal, 24(1): 23-34.

Lehtonen, V. 2011. Instrumentation and analysis of a railway embankment failure experiment. Research report of the Finnish Transport agency, 29/2011. Finnish Transport Agency, Helsinki.

Lehtonen, V. 2015. Modelling undrained shear strength and pore pressure based on an effective stress soil model in limit equilibrium method. PhD thesis, Tampere University of Technology, Tampere.

Lehtonen, V., Meehan, C., Länsivaara, T., and Mansikkamäki, J. 2015. Full-scale embankment failure test under simulated train loading. Géotechnique, 65(12): 961-974.

Leroueil, S., Magnan, J.P., and Tavenas, F. 1990. Embankments on soft clays. Ellis Horwood Limited.

Leroueil, S, Kabbaj, M., Tavenas, F., and Bouchard, R. 1985. Stress-strain-strain rate relation for the compressibility of sensitive natural clays. Géotechnique, 35(2): 159-180. 
Lo, K. Y. 1970. The operational strength of fissured clays. Géotechnique, 20(1): 57-74.

Lunne, T., and Andersen, K. 2007. Soft clay shear strength parameters for deep water geotechnical design. In Proceedings, 6th International Site Investigation and Geotechnics Conference, Confronting New Challenges and Sharing Knowledge, London. pp. 151-176.

Lunne, T., Berre, T., and Strandvik, S. 1997. Sample disturbance effects in soft low plastic Norwegian clay. In Proceedings of the Conference on Recent Developments in Soil and Pavement Mechanics, Rio de Janeiro, Brazil, 25-27 June. Balkema, Rotterdam. pp. 81-102. [Also published in Norwegian Geotechnical Institute, Publication 204.]

Mansikkamäki, J. 2015 Effective stress finite element stability analysis of an old railway embankment on soft clay. PhD thesis, Tampere University of Technology, Tampere.

Mansikkamäki, J. and Länsivaara, T. 2012. 3D stability analysis of a full-scale embankment failure experiment. In Proceedings of the $16^{\text {th }}$ Nordic geotechnical meeting, NGM, 9-12 May 2012, Copenhagen, Denmark. pp. 405-412.

Mansikkamäki, J. Lehtonen, V., and Länsivaara, T. 2011. Advanced stability analysis of a failure test on an old railway embankment. In Proceedings of Symposium International, GEORAIL 2011, Paris, France.

Mayne, P.W. 1983. Discussion: Undrained shear strength anisotropy of normally consolidated cohesive soils. Soils and Foundations, 23(4): 143-146.

NGI, 2011. Effekt av progressiv bruddutvikling for utbygging i områder med kvikkleire, Teknisk Notat, Document n. 20092128-00-10-TN. 
Ortigao J.A.R., and Collet, H. B. 1988 Errors caused by friction in field vane tests. In Vane Shear Strength Testing in Soils: Field and Laboratory Studies. ASTM International.

Pietruszczak, S.T., and Mroz, Z.1981. Finite element analysis of deformation of strain-softening materials. International Journal for Numerical Methods in Engineering, 17(3): 327-334.

Plaxis, B.V. 2012. User's manual of PLAXIS.

Ratahallintokeskus 2005. Radan stabiliteetin laskenta, olemassa olevat penkereet. Ratahallintokeskuksen julkaisuja B15, Ratahallintokeskus, Helsinki. (In Finnish. In English: Guidelines for embankments stability calculation by the Finnish Transport Agency, publication B15).

Rosenqvist, I.T. 1953. Considerations on the sensitivity of Norwegian quick-clays. Géotechnique, 3(5): 195-200.

Rosenqvist, I.T. 1966. Norwegian research into the properties of quick clay-a review. Engineering Geology, 1(6): 445-450.

Schanz, T., Vermeer, P.A., and Bonnier, P.G. 1999. The hardening soil model: formulation and verification. In Beyond 2000 in computational geotechnics. Edited by Balkema, Rotterdam. pp. 281-296.

Selänpää, J., Di Buò, B., Länsivaara, T., and D’Ignazio, M. 2017 In Press. Problems related to field vane testing in soft soil conditions and improved reliability of measurements using an innovative field vane device. IWLSC 2017, Trondheim, June 2017. Accepted for publication. 
SFS-EN ISO 14688-2 (2004). Geotechincal investigation and testing. Identification and classification of soil. Part 2: Principles for a classification

Skempton, A.W. 1964. Long-term stability of slopes. Geotechnique, 14(2): 75-102.

Thakur, V., Oset, F., Viklund, M., Strand, S.A., Gjeskiv, V., Christensen, S., and Fauskerud, O.A. 2014. En omforent anbefaling for bruk av anisotropifaktorer i prosjektering i norske leirer. Report $\mathrm{n}$. 1/2014. ISBN n. 978-82-410-0962-4.

Tiehallinto 2001. Teiden pohjarakenteden suunnitteluperusteet (In Finnish). Design manual by Finnish Road Authority. Helsinki.

Vermeer, P.A. and Brinkgreve, R.B.J. 1994. A new effective non-local strain-measure for softening plasticity. In Proceedings of $3^{\text {rd }}$ International Workshop on Localization and Bifurcation Theory for Soils and Rocks, Grenoble, September 1993. pp. 89-100.

Won, J.Y. 2013. Anisotropic strength ratio and plasticity index of natural clays. In Proceedings of the 18th International Conference on Soil Mechanics and Geotechnical Engineering, ICSMGE, 2-6 September 2013, Paris. pp. 445-448. 


\section{Figures captions}

Fig. 1: Varying stress paths along a slip surface (after Bjerrum 1973).

Fig. 2: Stratigraphy of the test site.

Fig. 3: General characteristics of Perniö clay, from samples taken over the test area.

Fig. 4: Instrumentation layout (after Lehtonen et al. 2015).

Fig. 5: Interpreted failure mechanism (modified after Lehtonen et al. 2015).

Fig. 6: Evolution of excess pore pressure and rate of excess pore pressure at different locations as a function of the applied load (adapted from Lehtonen et al. 2015)

Fig. 7: Idealized stress paths for Perniö clay.

Fig. 8: Shear strain versus time from inclinometers L2P1, L2P2, L2P3.

Fig. 9: (a) Typical effective stress paths and stress-strain curves for triaxial compression (TXC) and extension (TXE) tests (from Grimstad et al. 2012) and (b) stress-strain behavior in direct simple shear (DSS) tests (from Andresen et al. 2011) with definition of stress/strain quantities.

Fig. 10: Input parameters for NGI-ADPSoft model. The triaxial and DSS curves are presented in terms of deviatoric stress $\left(\left(\sigma_{y}-\sigma_{x}\right) / 2\right)$ and shear stress $\left(\tau_{x y}\right)$, respectively, versus strain. The symbols $\mathrm{x}$ and $\mathrm{y}$ refer to horizontal and vertical directions.

Fig. 11: Impact of shape parameters $c_{1}$ and $c_{2}$ on the post peak behavior modelled by NGIADPSoft soil model. In this example, $\gamma_{p}=1 \%$ and $\gamma_{r}=10 \%$.

Fig. 12: Peak values of $s_{u} / \sigma_{v}^{\prime}$ plotted against the overconsolidation ratio (OCR) and comparison with existing correlations for Scandinavian clays.

Fig. 13: Normalized $s_{u}{ }^{F V} / \sigma_{v}^{\prime}$ of Perniö clay versus $s_{u}{ }^{D S S} / \sigma_{v}^{\prime}$ and $s_{u}(m o b) / \sigma_{v}^{\prime}$ predicted by existing correlations for clays.

Fig.14: NGI-ADPSoft model curve fitting to TXC and TXE tests on Perniö clay.

Fig.15: Modelling of the sensitive clay layer.

Fig. 16: Anisotropic undrained shear strength profile for Perniö site.

Fig. 17: Finite Element mesh. 
Fig. 18: Comparison between the observed failure mechanism and the modelled shear bands from the FE analyses.

Fig. 19: Modelled versus observed Load-Time-Settlement.

Fig. 20: Measured and modelled horizontal displacements for section A-A.

Fig. 21: Hardening parameter $\kappa_{1}$ for an embankment settlement of (a) $0.11 \mathrm{~m}$ (at peak state) and (b) $1 \mathrm{~m}$ (at large strain).

Fig. 22: Hardening parameter $\kappa_{2}$ for an embankment settlement of (a) $0.11 \mathrm{~m}$ (at peak state) and (b) $1 \mathrm{~m}$ (at large strain).

Fig. 23: Effect of input peak shear strains on horizontal displacements. 


\section{Tables}

Table 1. Undrained shear strength anisotropy ratio of soft clays from triaxial and direct simple shear tests.

\begin{tabular}{|c|c|c|}
\hline Author & $\mathbf{S}_{\mathrm{u}}{ }^{\mathrm{DSS}} / \mathbf{s}_{\mathrm{u}}{ }^{\mathrm{A}}$ & $\mathbf{s}_{\mathrm{u}}{ }^{\mathrm{P}} / \mathbf{s}_{\mathrm{u}}{ }^{\mathrm{A}}$ \\
\hline Jamiolkowski et al. (1985) & $0.53-0.79$ & $0.51-0.61$ \\
\hline Ladd (1991) & $0.72-0.89$ & $0.5-0.81$ \\
\hline Karlsrud et al. (2005) (Norwegian clays) & $0.6-0.8$ & $0.3-0.55$ \\
\hline Lunne and Andersen (2007) & $0.78-0.82$ & $0.59-0.65$ \\
\hline $\begin{array}{l}\text { Karlsrud and Hernandez-Martinez (2013), Norwegian } \\
\text { low sensitive clays }\left(S_{t}<15\right)\end{array}$ & $0.57-0.82$ & $0.3-0.52$ \\
\hline $\begin{array}{l}\text { Karlsrud and Hernandez-Martinez (2013), Norwegian } \\
\text { sensitive clays }\left(S_{t}>15\right)\end{array}$ & $0.56-0.66$ & $0.22-0.32$ \\
\hline Thakur et al. (2014) Norwegian clays $(\mathrm{PI}<10 \%)$ & 0.63 & 0.35 \\
\hline Thakur et al. (2014) Norwegian clays (PI>10\%) & $0.63-0.80$ & $0.35-0.50$ \\
\hline
\end{tabular}


Table 2. Characteristics of Perniö clay.

\begin{tabular}{|c|c|c|}
\hline Parameter & Unit & Value \\
\hline Unit weight $\left(\gamma_{\text {tot }}\right)$ & $\mathrm{kN} / \mathrm{m}^{3}$ & 15.4 \\
\hline Water content (w) & $\%$ & $48-109$ \\
\hline Liquid limit $\left(w_{L}\right)$ & $\%$ & $38-82$ \\
\hline $\mathrm{s}_{\mathrm{u}}(\mathrm{FV})$ & $\mathrm{kPa}$ & $\begin{array}{l}9-13 \text { on top of the } \\
\text { layer, increasing } 1.15 \\
\mathrm{kPa} / \mathrm{m}\end{array}$ \\
\hline Remolded $s_{u}\left(s_{u}{ }^{r e}\right)$ & $\mathrm{kPa}$ & $<0.5$ \\
\hline Sensitivity $\left(S_{t}\right)$ & - & $23-69$ \\
\hline $\begin{array}{l}\text { Over consolidation ratio } \\
\text { (OCR) based on CRS tests }\end{array}$ & - & $\begin{array}{l}<1.5 \text { (soft sensitive } \\
\text { clay); > } 2 \text { (stiff clay) }\end{array}$ \\
\hline Clay content & $\%$ & $48-81$ \\
\hline
\end{tabular}


Table 3. General characteristics of Perniö dry crust.

\begin{tabular}{llll}
\hline Parameter & Unit & $\begin{array}{l}\text { Depth } \\
\mathbf{0 - 1} \mathbf{~ m}\end{array}$ & $\begin{array}{l}\text { Depth } \\
\mathbf{1 - 1 . 5} \mathbf{~ m}\end{array}$ \\
\hline Unit weight $\left(\gamma_{\text {tot }}\right)$ & $\mathrm{kN} / \mathrm{m}^{3}$ & 17 & $15-16$ \\
Water content $(\mathrm{w})$ & $\%$ & $40-50$ & $80-90$ \\
Liquid limit $\left(\mathrm{w}_{\mathrm{L}}\right)$ & $\%$ & $60-65$ & $75-85$ \\
Plastic limit $\left(\mathrm{w}_{\mathrm{P}}\right)$ & $\%$ & $30-35$ & $35-40$ \\
Plasticity index $(\mathrm{PI})$ & $\%$ & 30 & $40-45$ \\
Liquidity index $(\mathrm{LI})$ & - & $0.33-0.5$ & $1.11-1.13$ \\
Clay content & $\%$ & $51-58$ & $48-64$ \\
Activity & - & $0.38-0.52$ & $0.70-0.83$ \\
Degree of saturation $\left(\mathrm{S}_{\mathrm{r}}\right)$ & $\%$ & $80-90$ & 100 \\
\hline
\end{tabular}


Table 4. Input parameters for NGI-ADP and NGI-ADPSoft models.

\begin{tabular}{|c|c|c|c|c|c|c|c|}
\hline Parameter & Unit & Description & $\begin{array}{l}\text { Dry crust } \\
\text { (NGI-ADP) }\end{array}$ & Stiff clay & Soft clay & $\begin{array}{c}\text { Sensitive } \\
\text { clay }\end{array}$ & Silty clay \\
\hline $\begin{array}{l}\text { Material } \\
\text { type }\end{array}$ & - & $\begin{array}{l}\text { Material type used in } \\
\text { the calculation }\end{array}$ & Drained & Drained & Drained & Drained & Drained \\
\hline$\gamma_{\text {tot }}$ & - & Total unit weight & 16.5 & 15 & 15 & 15 & 17.8 \\
\hline $\mathrm{G}_{0} / \mathrm{S}_{\mathrm{u}}{ }^{\mathrm{A}}$ & & Initial stiffness & 700 & 700 & 700 & 700 & 700 \\
\hline $\mathrm{S}_{\mathrm{u}}^{\mathrm{A}}$ ref & $\mathrm{kPa}$ & $\begin{array}{l}\text { Reference active } \\
\text { shear strength }\end{array}$ & 35 & 22 & 17 & 19.4 & 22.5 \\
\hline $\mathrm{S}_{\mathrm{u}}^{\mathrm{A} \text { inc }}$ & $\mathrm{kPa} / \mathrm{m}$ & $\begin{array}{l}S_{u} \text { increase with } \\
\text { depth }\end{array}$ & -13 & -7.1 & 1.8 & 1.8 & 3 \\
\hline $\mathrm{y}_{\mathrm{ref}}$ & $\mathrm{m}$ & Reference depth & 0 & $6.3^{\dagger} / 5.8^{\ddagger}$ & $5.6^{\dagger} / 5.1^{\ddagger}$ & 3.8 & -8 \\
\hline$x_{\text {ref }}$ & $\mathrm{m}$ & $\begin{array}{l}\text { Reference } x- \\
\text { coordinate }\end{array}$ & -7 & $-8^{\dagger} / 4.7^{\ddagger}$ & $-8^{\dagger} / 4.7^{\ddagger}$ & 4.7 & 3 \\
\hline$\Delta \mathrm{y}_{\mathrm{ref}} / \Delta \mathrm{x}$ & - & $\begin{array}{l}\text { Reference depth } \\
\text { gradient }\end{array}$ & - & $-0.042^{\dagger} / 0^{\ddagger}$ & $-0.042^{\dagger} / 0^{\ddagger}$ & 0 & -0.08 \\
\hline$\gamma_{p}^{c}$ & $\%$ & $\begin{array}{l}\text { Shear strain at peak } \\
\text { in CAUC }\end{array}$ & 2 & 2 & 2 & 2 & 3 \\
\hline$\gamma_{p}^{\text {DSS }}$ & $\%$ & $\begin{array}{l}\text { Shear strain at peak } \\
\text { in DSS }\end{array}$ & 2 & 4 & 4 & 4 & 3 \\
\hline$\gamma_{p}^{E}$ & $\%$ & $\begin{array}{l}\text { Shear strain at peak } \\
\text { in CAUE }\end{array}$ & 2 & 8 & 8 & 8 & 3 \\
\hline$\gamma_{r}^{c}$ & $\%$ & $\begin{array}{l}\text { Shear strain at } \\
\text { residual state in } \\
\text { CAUC }\end{array}$ & - & 25 & 25 & 25 & 25 \\
\hline$\gamma_{r}^{\text {DSS }}$ & $\%$ & $\begin{array}{l}\text { Shear strain at } \\
\text { residual state in DSS }\end{array}$ & - & 25 & 25 & 25 & 25 \\
\hline$\gamma_{r}^{E}$ & $\%$ & $\begin{array}{l}\text { Shear strain at } \\
\text { residual state in } \\
\text { CAUE }\end{array}$ & - & 25 & 25 & 25 & 25 \\
\hline$\tau_{0} / s_{u}{ }^{A}$ & - & Initial mobilization & 0 & 0.11 & 0.3 & 0.3 & 0.4 \\
\hline $\mathrm{s}_{\mathrm{u}}{ }^{\mathrm{P}} / \mathrm{s}_{\mathrm{u}}{ }^{\mathrm{A}}$ & - & $\begin{array}{l}\text { Normalized passive } \\
\text { strength }\end{array}$ & $0.88^{*}$ & 0.5 & 0.5 & 0.5 & 0.5 \\
\hline $\mathrm{s}_{\mathrm{u}}{ }^{\mathrm{USS}} / \mathrm{s}_{\mathrm{u}}{ }^{\mathrm{A}}$ & - & $\begin{array}{l}\text { Normalized DSS } \\
\text { strength }\end{array}$ & $0.92^{*}$ & 0.65 & 0.65 & 0.65 & 0.65 \\
\hline $\mathrm{s}_{\mathrm{ur}}^{\mathrm{A}} / \mathrm{s}_{\mathrm{u}}{ }^{\mathrm{A}}$ & - & $\begin{array}{l}\text { Normalized residual } \\
\text { active strength }\end{array}$ & - & 0.5 & 0.5 & 0.4 & 0.5 \\
\hline $\mathrm{S}_{\mathrm{ur}}{ }^{\mathrm{USS}} / \mathrm{s}_{\mathrm{u}}{ }^{\mathrm{A}}$ & - & $\begin{array}{l}\text { Normalized residual } \\
\text { DSS strength }\end{array}$ & - & 0.5 & 0.5 & 0.4 & 0.5 \\
\hline $\mathrm{s}_{\mathrm{ur}}{ }^{\mathrm{r}} / \mathrm{s}_{\mathrm{u}}{ }^{\mathrm{A}}$ & - & $\begin{array}{l}\text { Normalized residual } \\
\text { passive strength }\end{array}$ & - & 0.5 & 0.5 & 0.4 & 0.5 \\
\hline$v^{\prime}$ & - & Poisson's ratio & 0.495 & 0.495 & 0.495 & 0.495 & 0.495 \\
\hline $\mathrm{K}_{0}$ & - & $\begin{array}{l}\text { Lateral stress } \\
\text { coefficient }\end{array}$ & 1 & 0.77 & 0.65 & 0.65 & 0.65 \\
\hline$c_{1}$ & - & Shape parameter & - & 1 & 1 & 1 & 1 \\
\hline $\mathrm{c}_{2}$ & - & Shape parameter & - & 1 & 1 & 1 & 1 \\
\hline$\alpha$ & - & $\begin{array}{l}\text { Non-local strain } \\
\text { parameter }\end{array}$ & - & 2 & 2 & 2 & 2 \\
\hline$I_{\text {int }}$ & $\mathrm{m}$ & Internal length & - & 0.4 & 0.4 & 0.4 & 0.4 \\
\hline
\end{tabular}


Table 5. Input parameters for the Hardening Soil model.

\begin{tabular}{|c|c|c|c|c|c|}
\hline Parameter & Unit & Description & Embankment & Sand fill & Lower sand \\
\hline Material type & & $\begin{array}{l}\text { Material type used in the } \\
\text { calculation }\end{array}$ & Drained & Drained & Drained \\
\hline$\gamma_{\text {tot }}$ & $\mathrm{kN} / \mathrm{m}^{3}$ & Total unit weight & 21 & 19 & 19 \\
\hline$E_{50}{ }^{\text {ref }}$ & $\mathrm{MPa}$ & $\begin{array}{l}\text { Secant stiffness for CD } \\
\text { triaxial }\end{array}$ & 100 & 30 & 30 \\
\hline $\mathrm{E}_{\mathrm{oed}}^{\text {ref }}$ & $\mathrm{MPa}$ & $\begin{array}{l}\text { Tangent oedometer } \\
\text { stiffness }\end{array}$ & 100 & 30 & 30 \\
\hline $\mathrm{E}_{\mathrm{ur}}^{\mathrm{ref}}$ & $\mathrm{MPa}$ & $\begin{array}{l}\text { Unloading/Reloading } \\
\text { stiffness }\end{array}$ & $250^{*}$ & 90 & 90 \\
\hline $\mathrm{m}$ & - & $\begin{array}{l}\text { Power for stress } \\
\text { dependent stiffness }\end{array}$ & 0.5 & 0.5 & 0.5 \\
\hline$c^{\prime}$ & $\mathrm{kPa}$ & Effective cohesion & 1 & 1 & 1 \\
\hline$p^{\text {ref }}$ & $\mathrm{kPa}$ & $\begin{array}{l}\text { Reference stress for } \\
\text { stiffness }\end{array}$ & 100 & 100 & 100 \\
\hline $\mathrm{POP}^{* *}$ & $\mathrm{kPa}$ & Pre-overburden pressure & 0 & 20 & 0 \\
\hline$\phi^{\prime}$ & $\circ$ & Friction angle & 38 & 36 & 36 \\
\hline$\psi$ & $\circ$ & Dilatancy angle & 8 & 6 & 6 \\
\hline$v^{\prime}$ & - & Poisson's ratio & 0.3 & 0.3 & 0.3 \\
\hline
\end{tabular}

$\mathrm{E}_{\mathrm{ur}}{ }^{\text {ret }}=2.5 \mathrm{E}_{50}{ }^{\text {ret }}$ according to Mansikkamäki (2015).

"POP $=\sigma_{p}^{\prime}-\sigma_{v 0}^{\prime}$ 
Table 6. Calculated failure load in Perniö failure test for scenarios with different input $\mathrm{s}_{\mathrm{u}}$.

\begin{tabular}{|c|c|c|c|c|c|c|}
\hline Input $s_{u}$ & Anisotropy & $\begin{array}{l}\text { Strain } \\
\text { softening }\end{array}$ & Layer & $\begin{array}{l}\mathrm{S}_{\mathrm{u}}^{\mathrm{A}} \text { ref } \\
(\mathrm{kPa})\end{array}$ & $\begin{array}{l}\mathrm{S}_{\mathrm{u} \text { inc }}^{\mathrm{A}} \\
(\mathrm{kPa} / \mathrm{m})\end{array}$ & $\begin{array}{l}\text { Failure load } \\
(\mathrm{kPa})\end{array}$ \\
\hline$s_{\mathrm{u}}\left(\right.$ peak values) ${ }^{*}$ & Yes & Yes & - & - & - & 80.8 \\
\hline$s_{u}$ (peak values) & Yes & No & Stiff clay & 22 & -7.1 & 85.8 \\
\hline$\left[\mathrm{s}_{\mathrm{ur}}^{\mathrm{P}} / \mathrm{s}_{\mathrm{u}}{ }^{\mathrm{A}}=0.5\right.$ & & & Soft clay & 17 & 1.8 & \\
\hline $\mathrm{s}_{\mathrm{ur}}{ }^{\mathrm{DSS}} / \mathrm{s}_{\mathrm{u}}{ }^{\mathrm{A}}=0.65$ & & & Sensitive clay & 19.4 & 1.8 & \\
\hline $\left.\mathrm{s}_{\mathrm{ur}}{ }^{\mathrm{A}} / \mathrm{s}_{\mathrm{u}}{ }^{\mathrm{A}}=1\right]$ & & & Silty clay & 22.5 & 3 & \\
\hline$s_{u}{ }^{\text {avg }}=\left(s_{u}{ }^{A}+s_{u}{ }^{D S S}+s_{u}{ }^{P}\right) / 3$ & No & No & Stiff clay & 16.1 & -5.4 & 88 \\
\hline$\left[\mathrm{s}_{\mathrm{u}}^{\mathrm{P}} / \mathrm{s}_{\mathrm{u}}{ }^{\mathrm{A}}=\mathrm{s}_{\mathrm{ur}}^{\mathrm{P}} / \mathrm{s}_{\mathrm{u}}{ }^{\mathrm{A}}=1\right.$ & & & Soft clay & 12.3 & 1.31 & \\
\hline $\mathrm{s}_{\mathrm{u}}{ }^{\mathrm{DSS}} / \mathrm{s}_{\mathrm{u}}{ }^{\mathrm{A}}=\mathrm{s}_{\mathrm{ur}}{ }^{\mathrm{DSS}} / \mathrm{s}_{\mathrm{u}}{ }^{\mathrm{A}}=1$, & & & Sensitive clay & 14 & 1.31 & \\
\hline $\left.\mathrm{s}_{\mathrm{ur}}{ }^{\mathrm{A}} / \mathrm{s}_{\mathrm{u}}{ }^{\mathrm{A}}=1\right]$ & & & Silty clay & 16.3 & 2.2 & \\
\hline $\mathbf{s}_{\mathrm{u}}{ }^{\text {Dss }}$ & No & No & Stiff clay & 14.6 & -4.9 & 80.5 \\
\hline$\left[\mathrm{s}_{\mathrm{u}}^{\mathrm{P}} / \mathrm{s}_{\mathrm{u}}{ }^{\mathrm{A}}=\mathrm{s}_{\mathrm{ur}}{ }^{\mathrm{P}} / \mathrm{s}_{\mathrm{u}}{ }^{\mathrm{A}}=1\right.$, & & & Soft clay & 11.2 & 1.2 & \\
\hline $\mathrm{S}_{\mathrm{u}}{ }^{\mathrm{DSS}} / \mathrm{S}_{\mathrm{u}}{ }^{\mathrm{A}}=\mathrm{s}_{\mathrm{ur}}{ }^{\mathrm{DSS}} / \mathrm{S}_{\mathrm{u}}{ }^{\mathrm{A}}=1$, & & & Sensitive clay & 12.7 & 1.2 & \\
\hline $\left.\mathrm{s}_{\mathrm{ur}}{ }^{\mathrm{A}} / \mathrm{s}_{\mathrm{u}}^{\mathrm{A}}=1\right]$ & & & Silty clay & 14.7 & 1.95 & \\
\hline $\begin{array}{l}S_{\mathrm{u}}{ }^{\mathrm{FV}}(\mathrm{FV} \text { average, corrected } \\
\text { values) }\end{array}$ & No & No & Stiff clay & 13.7 & -4.6 & 73.9 \\
\hline$\left[\mathrm{s}_{\mathrm{u}}^{\mathrm{P}} / \mathrm{s}_{\mathrm{u}}{ }^{\mathrm{A}}=\mathrm{s}_{\mathrm{ur}}{ }^{\mathrm{P}} / \mathrm{s}_{\mathrm{u}}{ }^{\mathrm{A}}=1\right.$, & & & Soft clay & 10.5 & 1.15 & \\
\hline $\mathrm{s}_{\mathrm{u}}{ }^{\mathrm{DSS}} / \mathrm{s}_{\mathrm{u}}{ }^{\mathrm{A}}=\mathrm{s}_{\mathrm{ur}}{ }^{\mathrm{DSS}} / \mathrm{s}_{\mathrm{u}}{ }^{\mathrm{A}}=1$, & & & Sensitive clay & 12 & 1.15 & \\
\hline $\left.\mathrm{s}_{\mathrm{ur}}^{\mathrm{A}} / \mathrm{s}_{\mathrm{u}}^{\mathrm{A}}=1\right]$ & & & Silty clay & 14 & 1.85 & \\
\hline
\end{tabular}

*Input parameters from Table 4. 


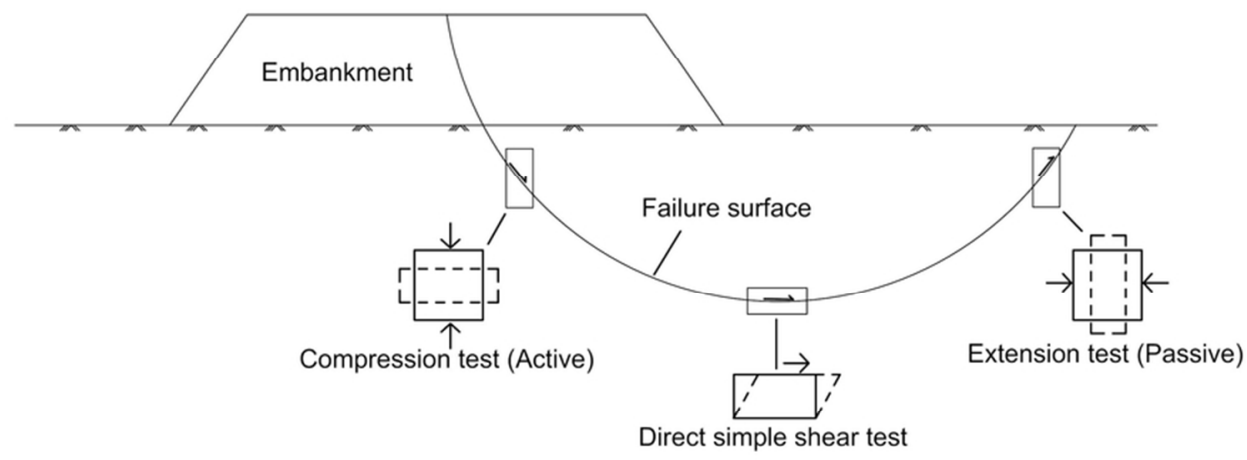

Fig. 1: Varying stress paths along a slip surface (after Bjerrum 1973).

Fig. 1

$38 \times 17 \mathrm{~mm}(600 \times 600 \mathrm{DPI})$ 


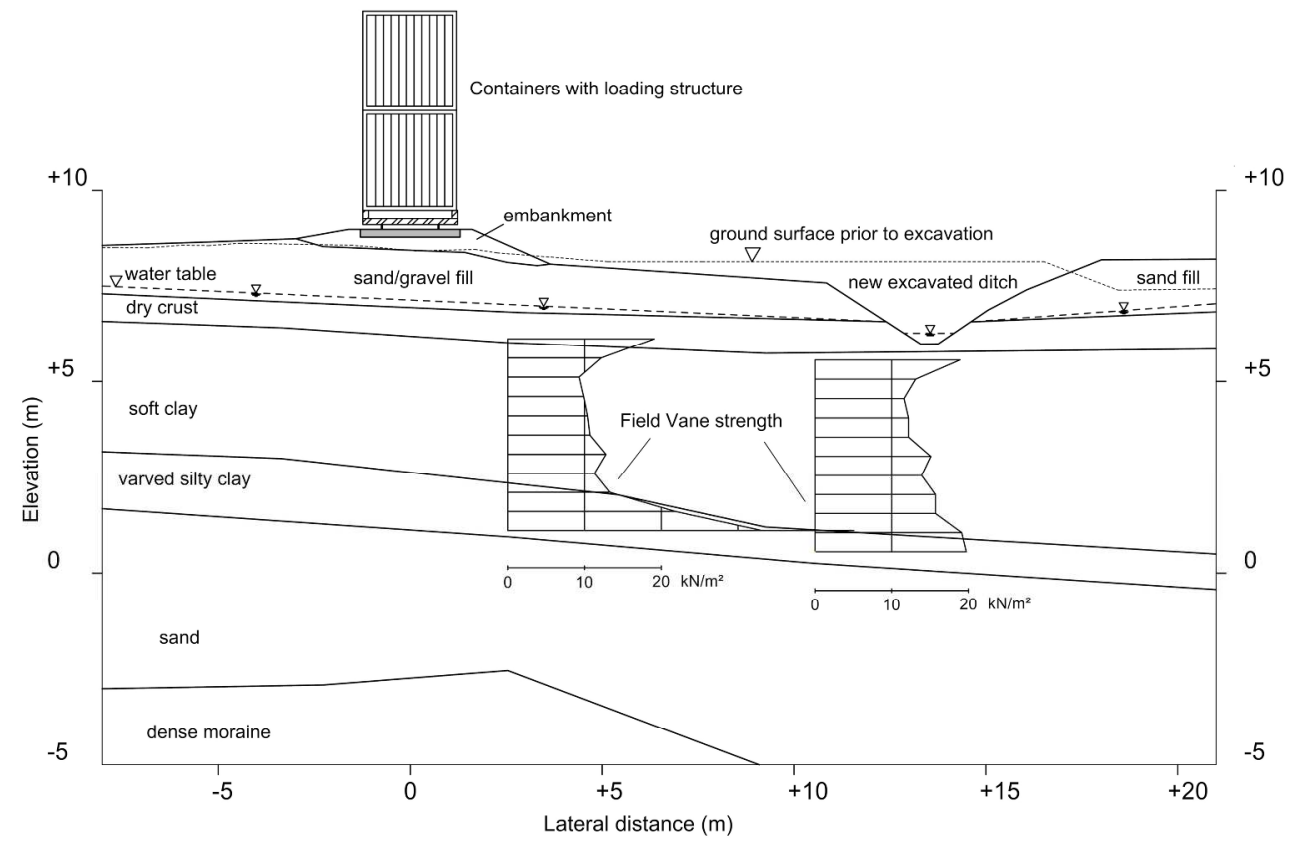

Fig. 2: Stratigraphy of the test site.

Fig. 2

$125 \times 85 \mathrm{~mm}(600 \times 600$ DPI $)$ 

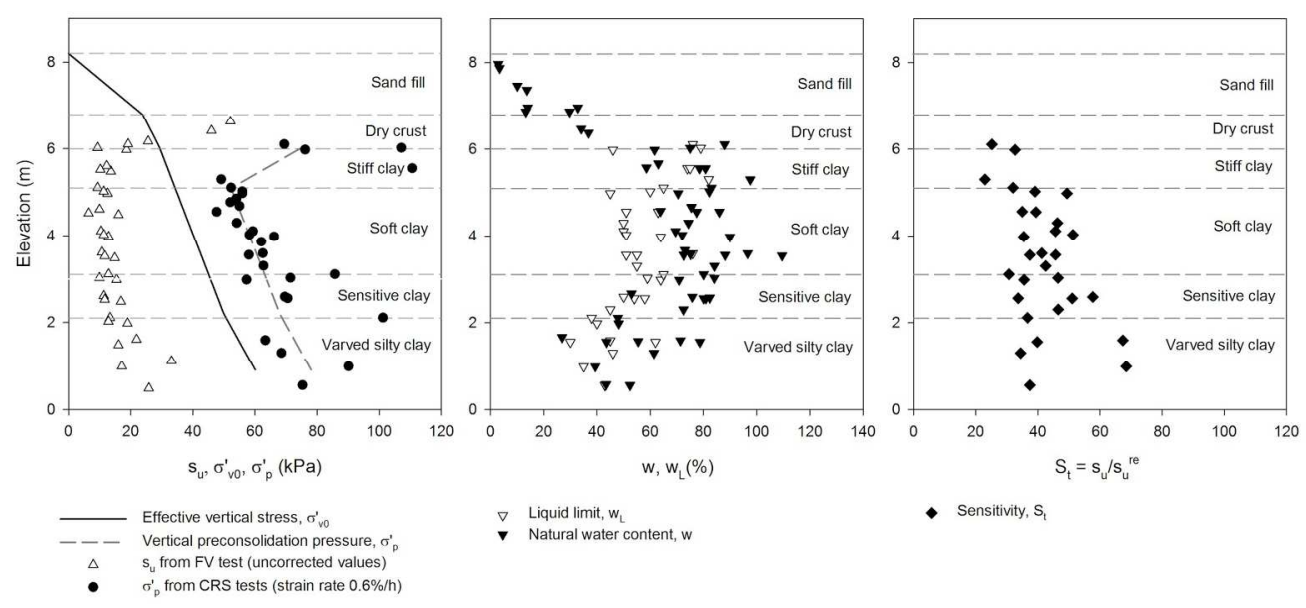

$\nabla$ Liquid limit, $\mathrm{w}_{\mathrm{L}}$

- Sensitivity, $\mathrm{S}_{\text {, }}$

Fig. 3: General characteristics of Perniö clay, from samples taken over the test area. Fig. 3

$186 \times 86 \mathrm{~mm}(300 \times 300 \mathrm{DPI})$ 


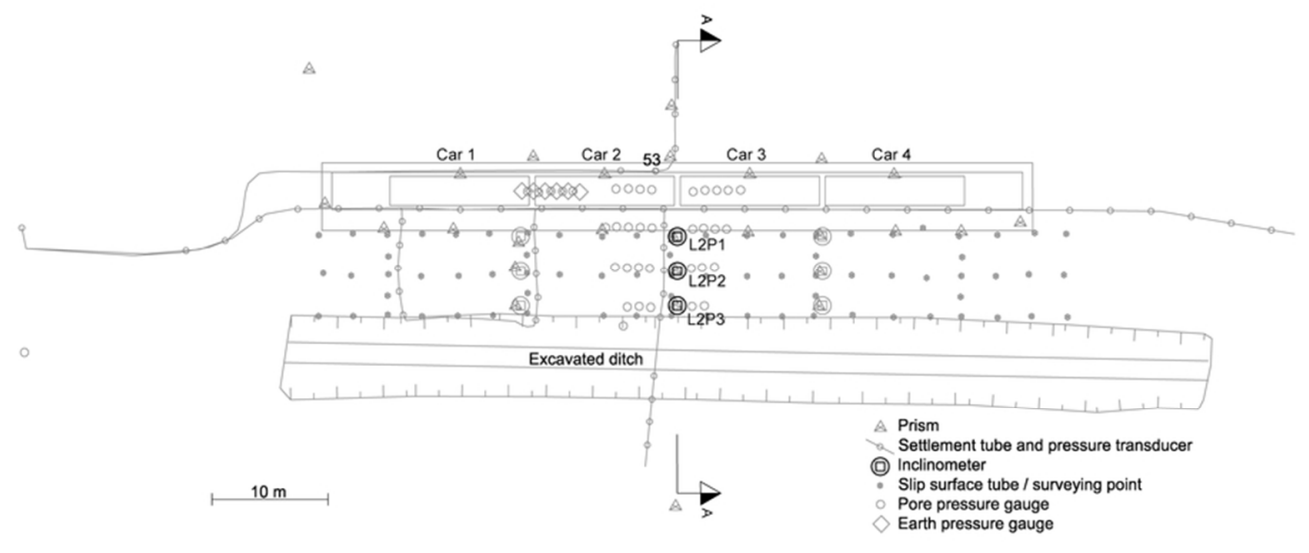

Fig. 4: Instrumentation layout (after Lehtonen et al. 2015).

Fig. 4

$77 \times 32 \mathrm{~mm}(300 \times 300$ DPI $)$ 


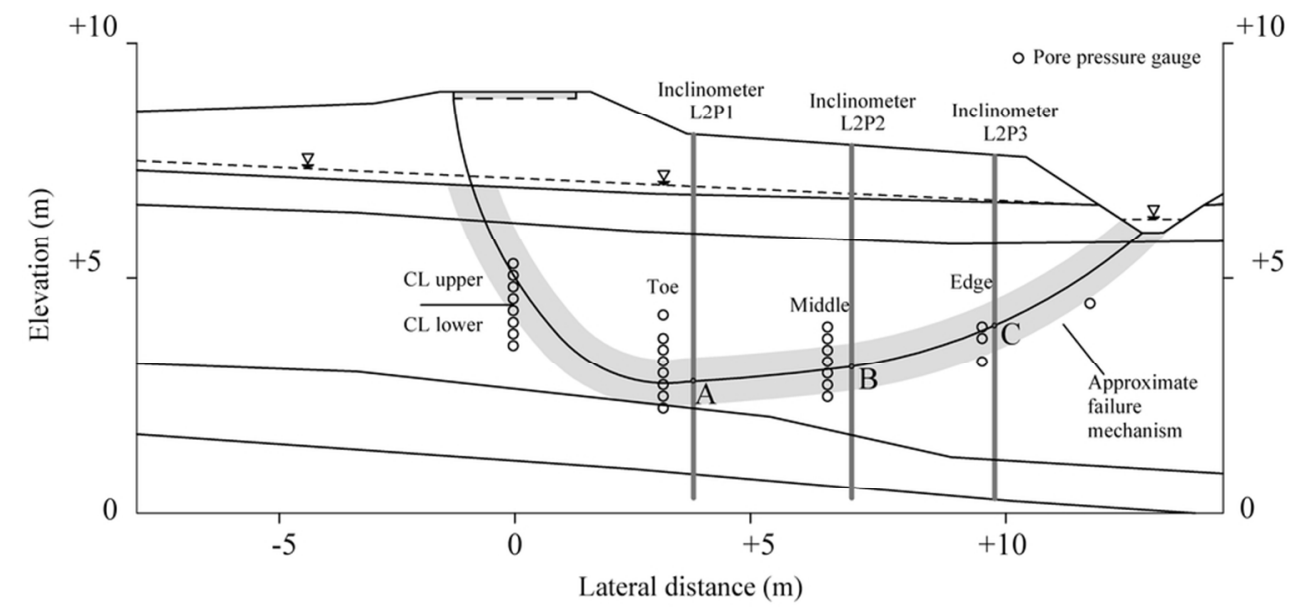

Fig. 5: Interpreted failure mechanism (modified after Lehtonen et al. 2015).

Fig. 5

$87 \times 41 \mathrm{~mm}(300 \times 300 \mathrm{DPI})$ 


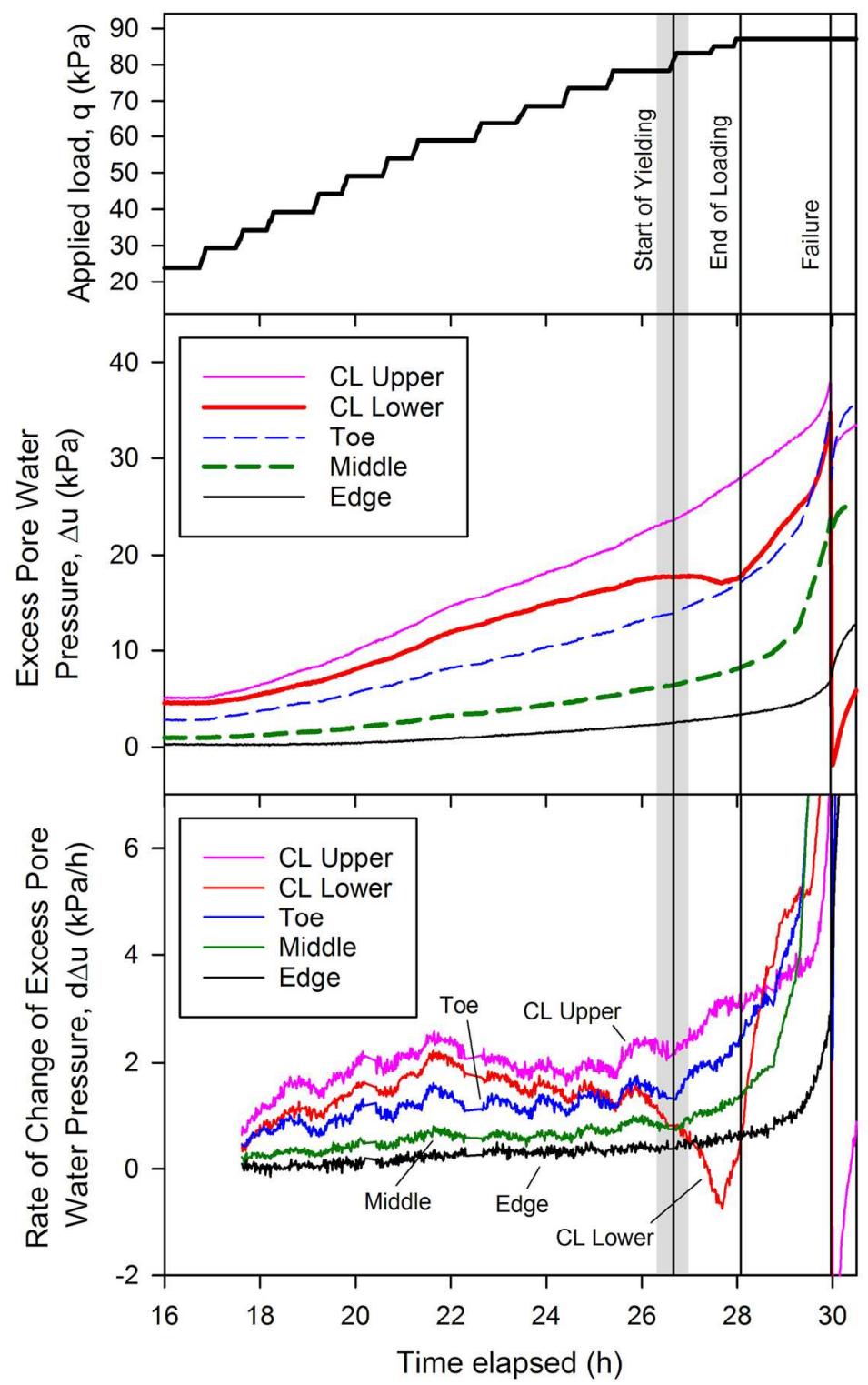

Fig. 6: Evolution of excess pore pressure and rate of excess pore pressure at different locations as a function of the applied load (adapted from Lehtonen et al. 2015)

Fig. 6

$129 \times 204 \mathrm{~mm}(300 \times 300 \mathrm{DPI})$ 


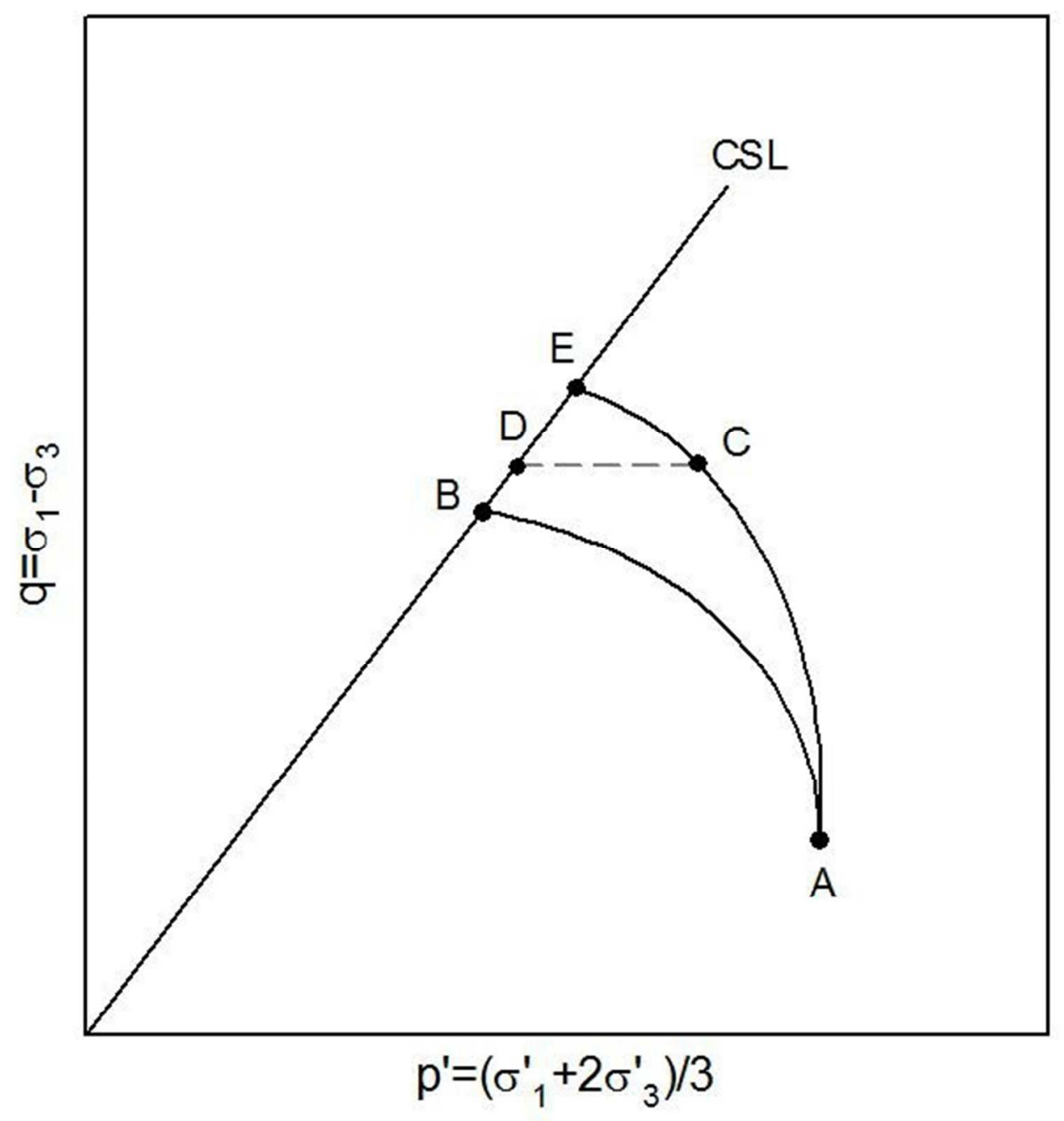

Fig. 7: Idealized stress paths for Perniö clay.

Fig. 7

$164 \times 173 \mathrm{~mm}(96 \times 96$ DPI) 


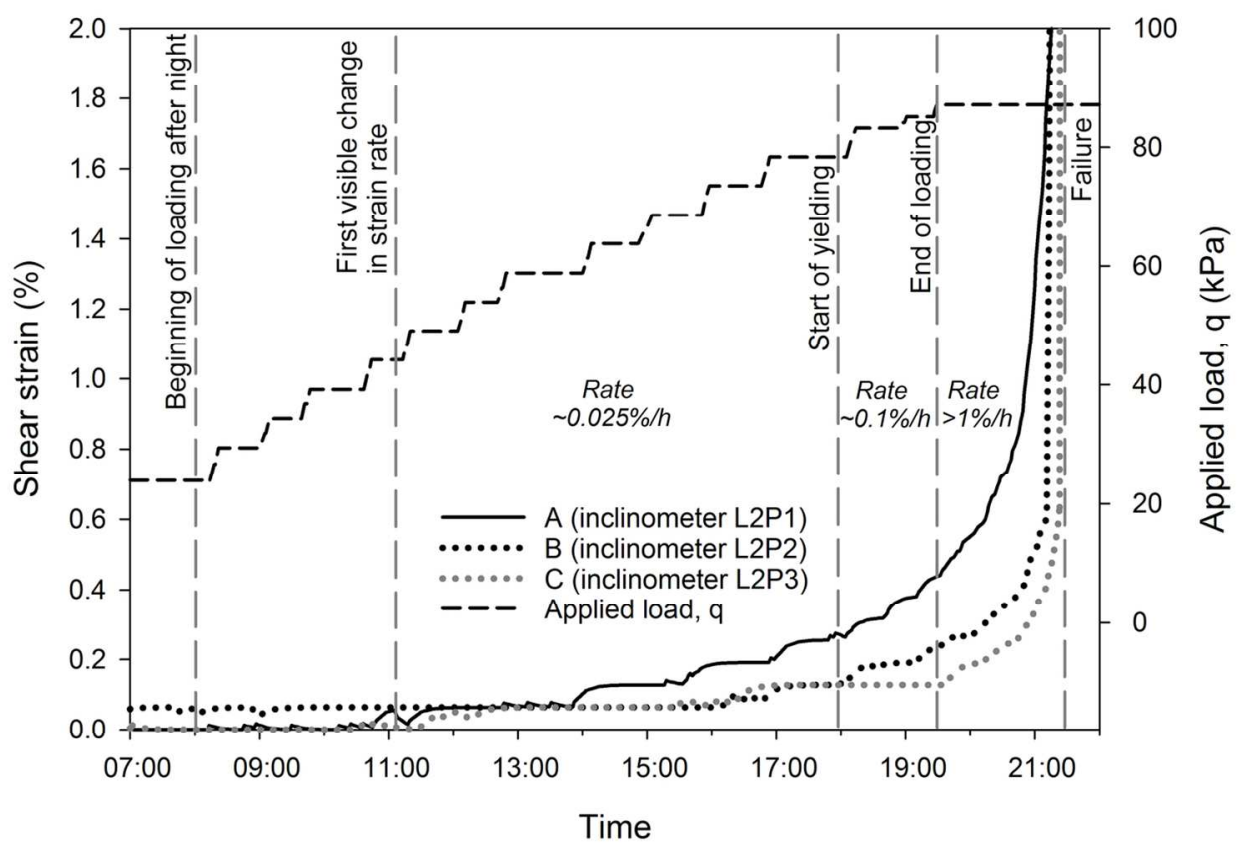

Fig. 8: Shear strain versus time from inclinometers L2P1, L2P2, L2P3.

Fig. 8

$126 \times 88 \mathrm{~mm}(300 \times 300 \mathrm{DPI})$ 

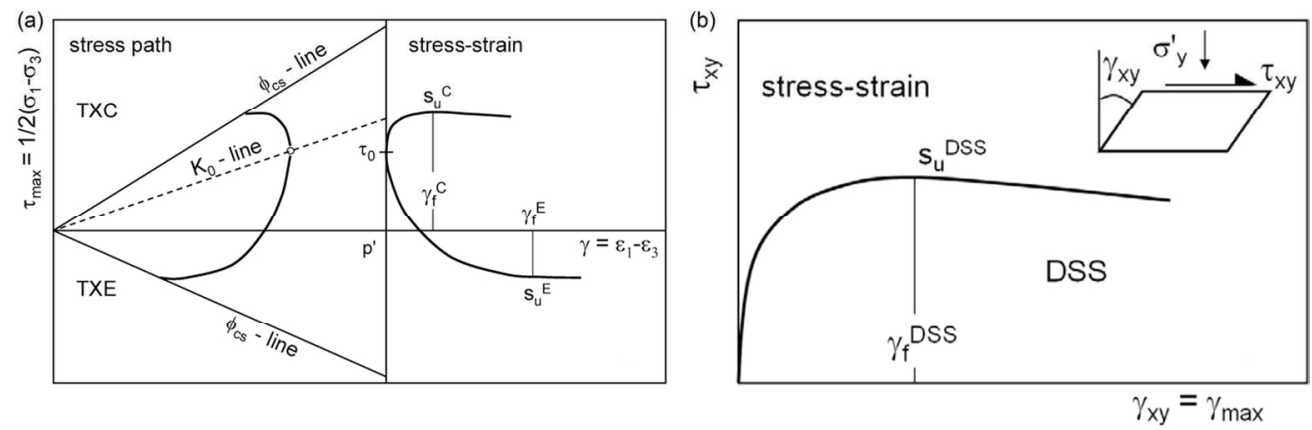

Fig. 9: (a) Typical effective stress paths and stress-strain curves for triaxial compression (TXC) and extension (TXE) tests (from Grimstad et al. 2012) and (b) stress-strain behavior in direct simple shear (DSS) tests (from Andresen et al. 2011) with definition of stress/strain quantities.

Fig. 9

$59 \times 19 \mathrm{~mm}(600 \times 600 \mathrm{DPI})$ 


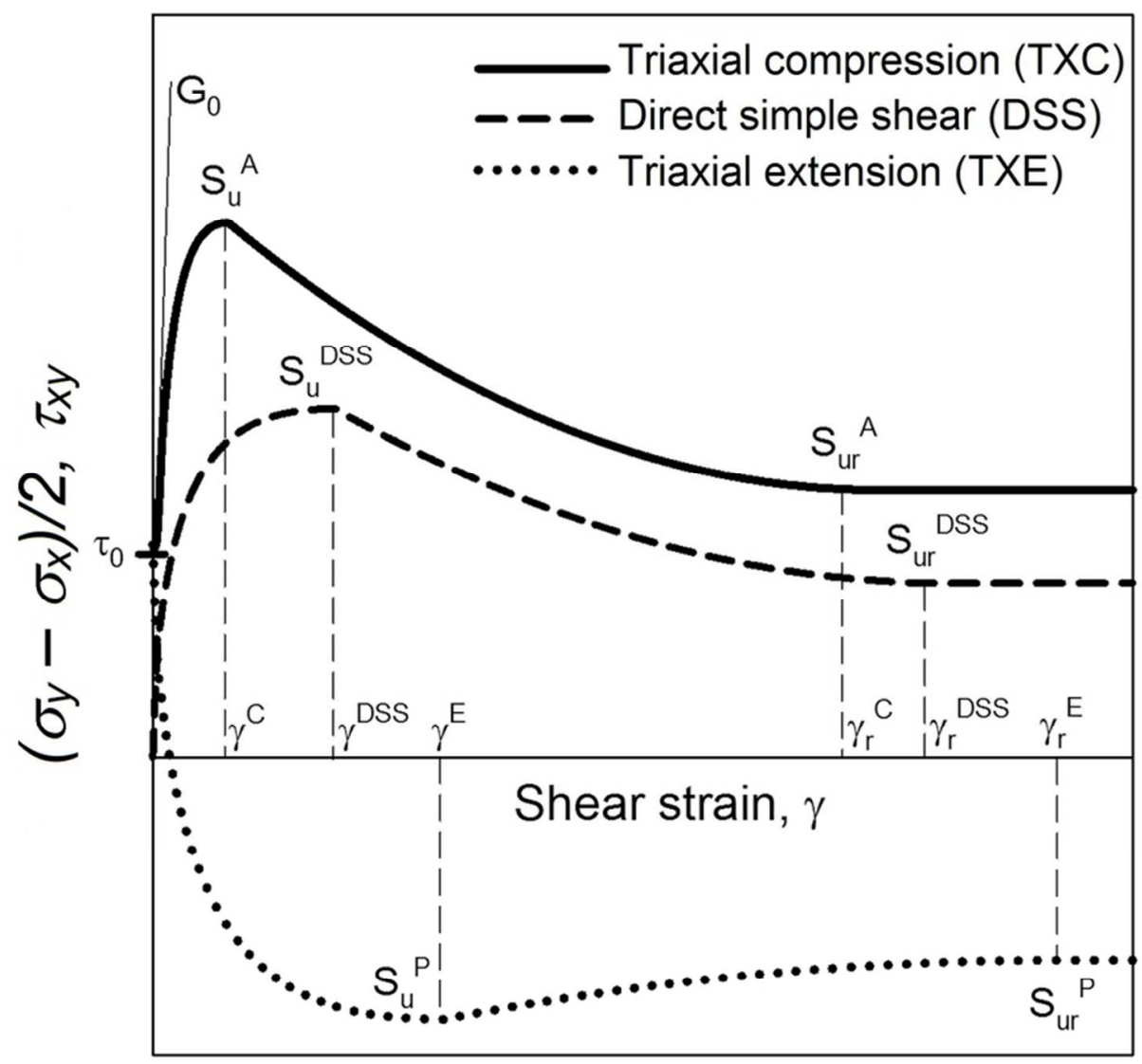

Fig. 10: Input parameters for NGI-ADPSoft model. The triaxial and DSS curves are presented in terms of deviatoric stress $\left(\left(\sigma_{y}-\sigma_{x}\right) / 2\right)$ and shear stress $\left(T_{x y}\right)$, respectively, versus strain. The symbols $x$ and $y$ refer to horizontal and vertical directions.

Fig. 10

$79 \times 72 \mathrm{~mm}(300 \times 300 \mathrm{DPI})$ 


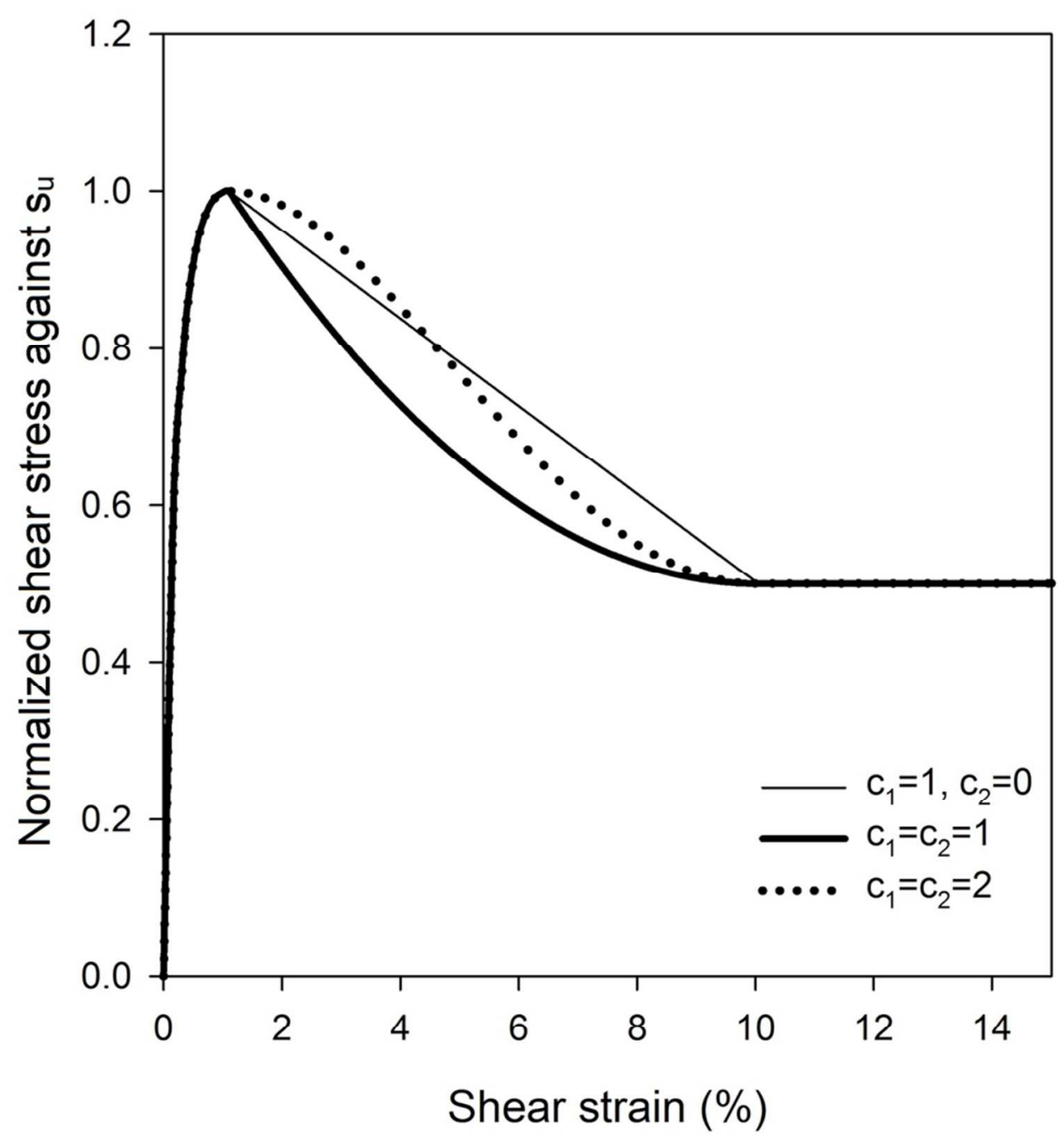

Fig. 11: Impact of shape parameters $c_{1}$ and $c_{2}$ on the post peak behavior modelled by NGI-ADPSoft soil model. In this example, $\gamma_{p}=1 \%$ and $\gamma_{r}=10 \%$.

Fig. 11

$85 \times 88 \mathrm{~mm}(300 \times 300$ DPI $)$ 


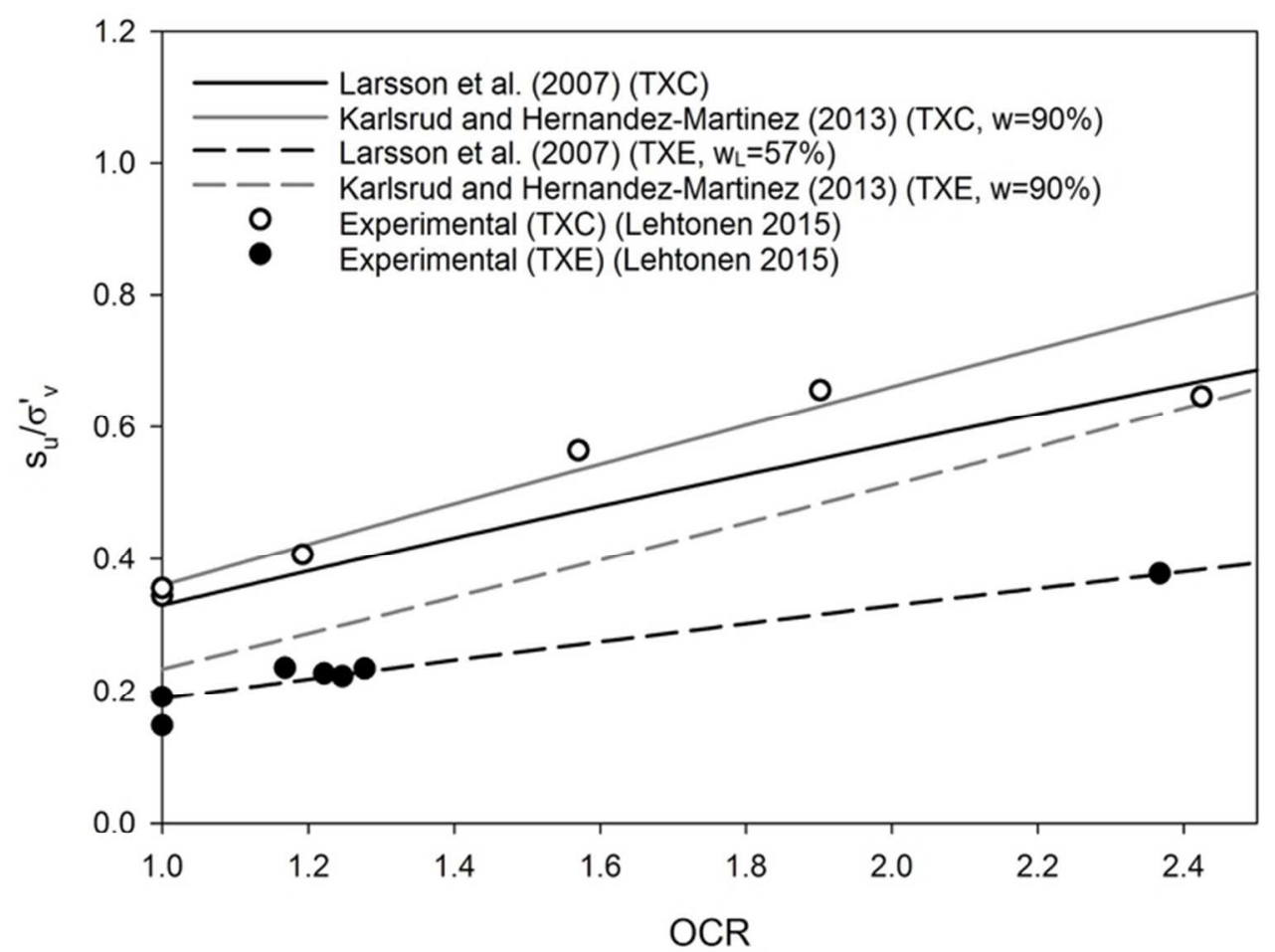

Fig. 12: Peak values of $\mathrm{S}_{\mathrm{u}} / \sigma_{\mathrm{v}}^{\prime}$ plotted against the overconsolidation ratio (OCR) and comparison with existing correlations for Scandinavian clays.

Fig. 12

$64 \times 48 \mathrm{~mm}(300 \times 300$ DPI $)$ 


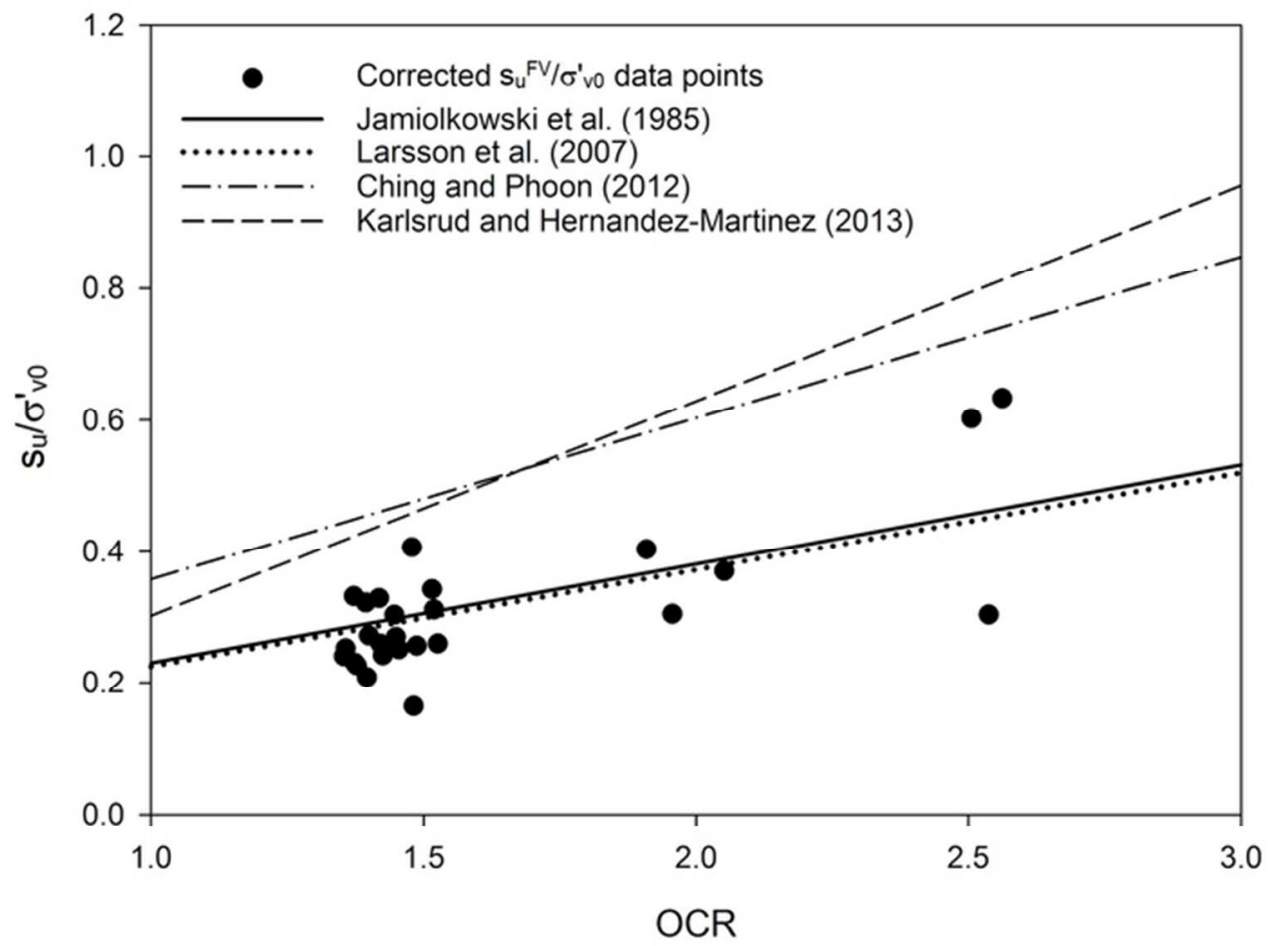

Fig. 13: Normalized $\mathrm{S}_{u}{ }^{\mathrm{FV}} / \sigma^{\prime}{ }_{v}$ of Perniö clay versus $\mathrm{S}_{\mathrm{u}}{ }^{\mathrm{DSS}} / \sigma^{\prime}{ }_{v}$ and $\mathrm{S}_{\mathrm{u}}(\mathrm{mob}) / \sigma^{\prime}$ v predicted by existing correlations for clays.

Fig. 13

$60 \times 45 \mathrm{~mm}(300 \times 300 \mathrm{DPI})$ 


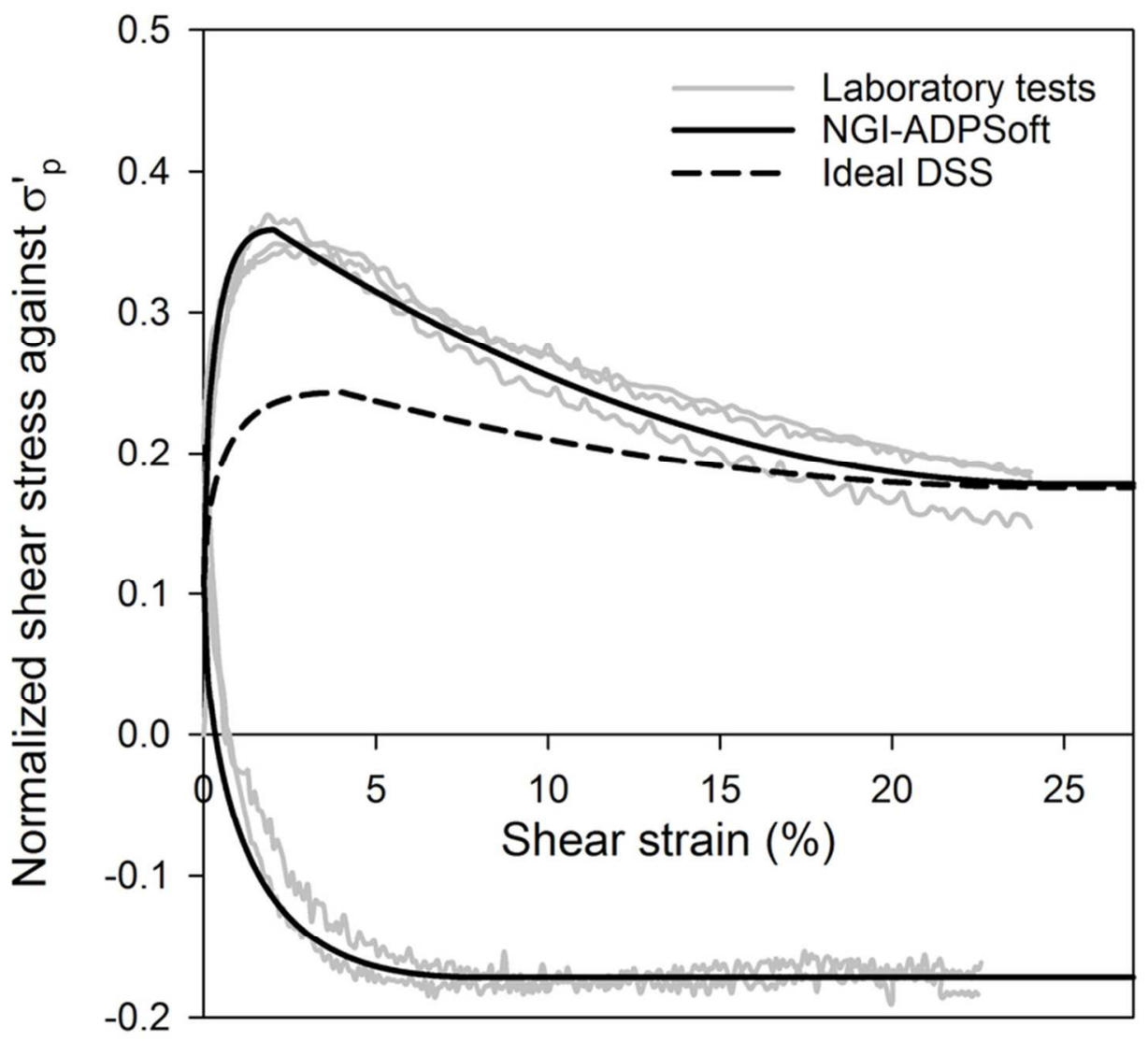

Fig.14: NGI-ADPSoft model curve fitting to TXC and TXE tests on Perniö clay. Fig. 14

$75 \times 65 \mathrm{~mm}(300 \times 300$ DPI $)$ 


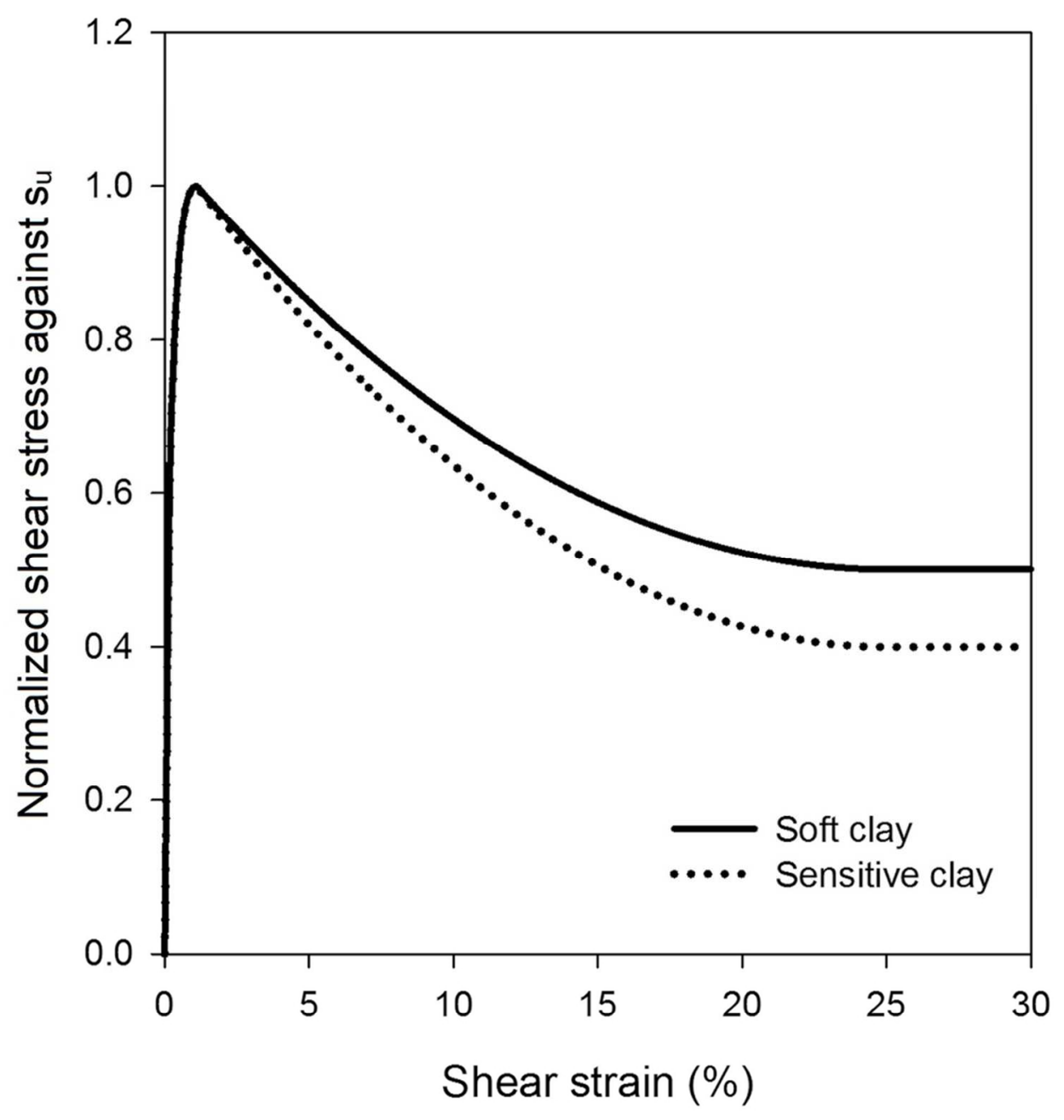

Fig.15: Modelling of the sensitive clay layer.

Fig. 15

$87 \times 89 \mathrm{~mm}(300 \times 300$ DPI $)$ 


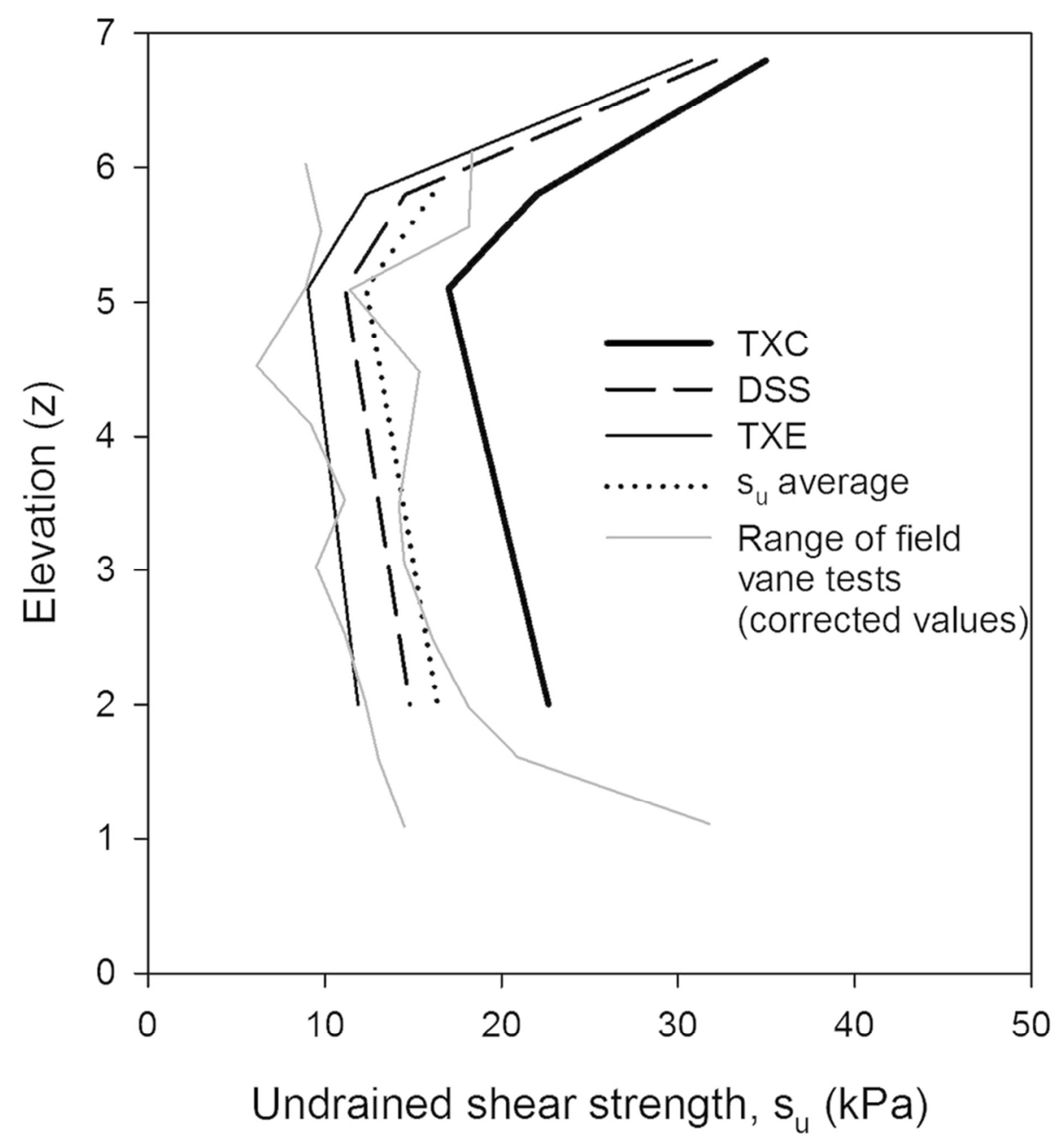

Fig. 16: Anisotropic undrained shear strength profile for Perniö site. Fig. 16

$87 \times 89 \mathrm{~mm}(300 \times 300$ DPI $)$ 


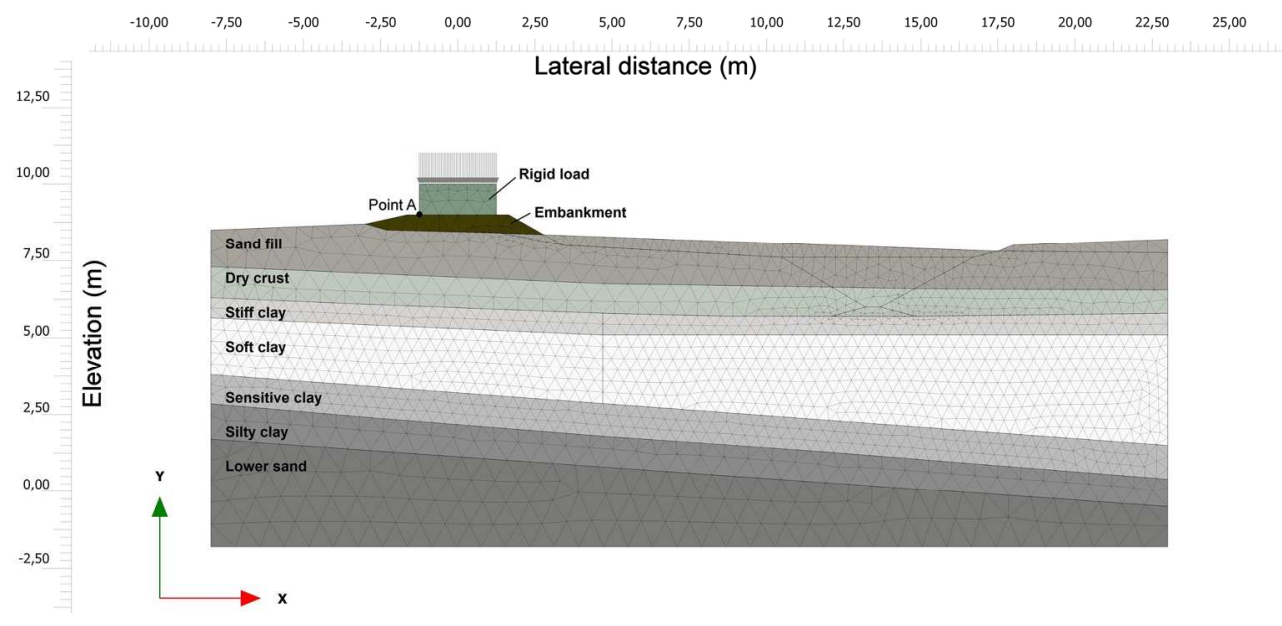

Fig. 17: Finite Element mesh.

Fig. 17

$85 \times 40 \mathrm{~mm}(600 \times 600$ DPI $)$ 


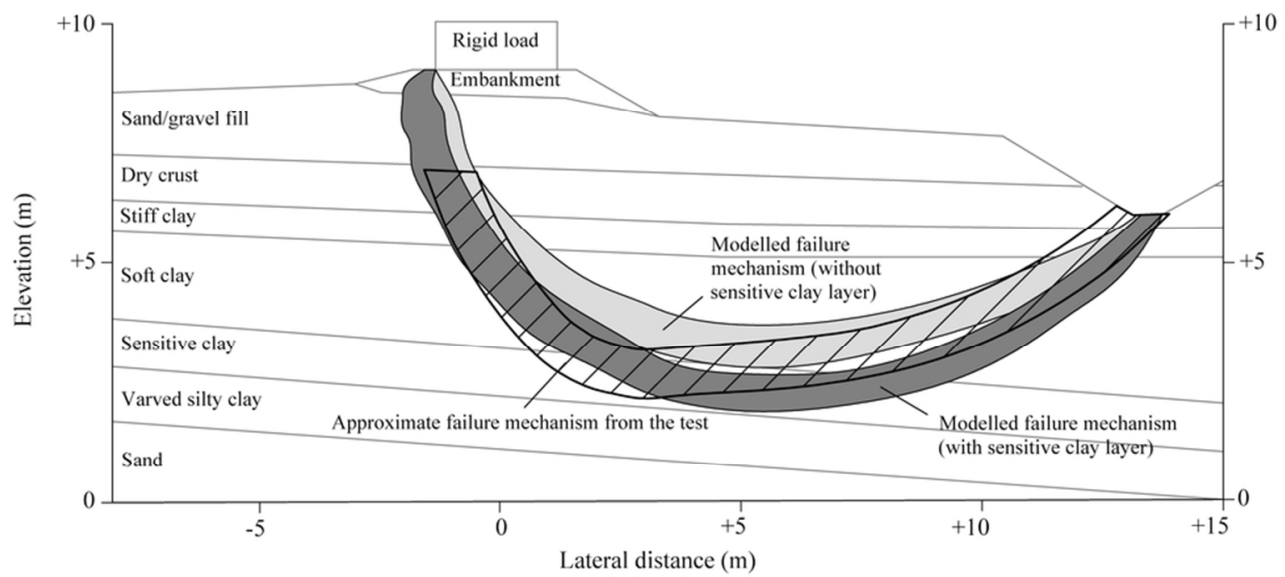

Fig. 18: Comparison between the observed failure mechanism and the modelled shear bands from the FE analyses.

Fig. 18

$83 \times 37 \mathrm{~mm}(300 \times 300 \mathrm{DPI})$ 


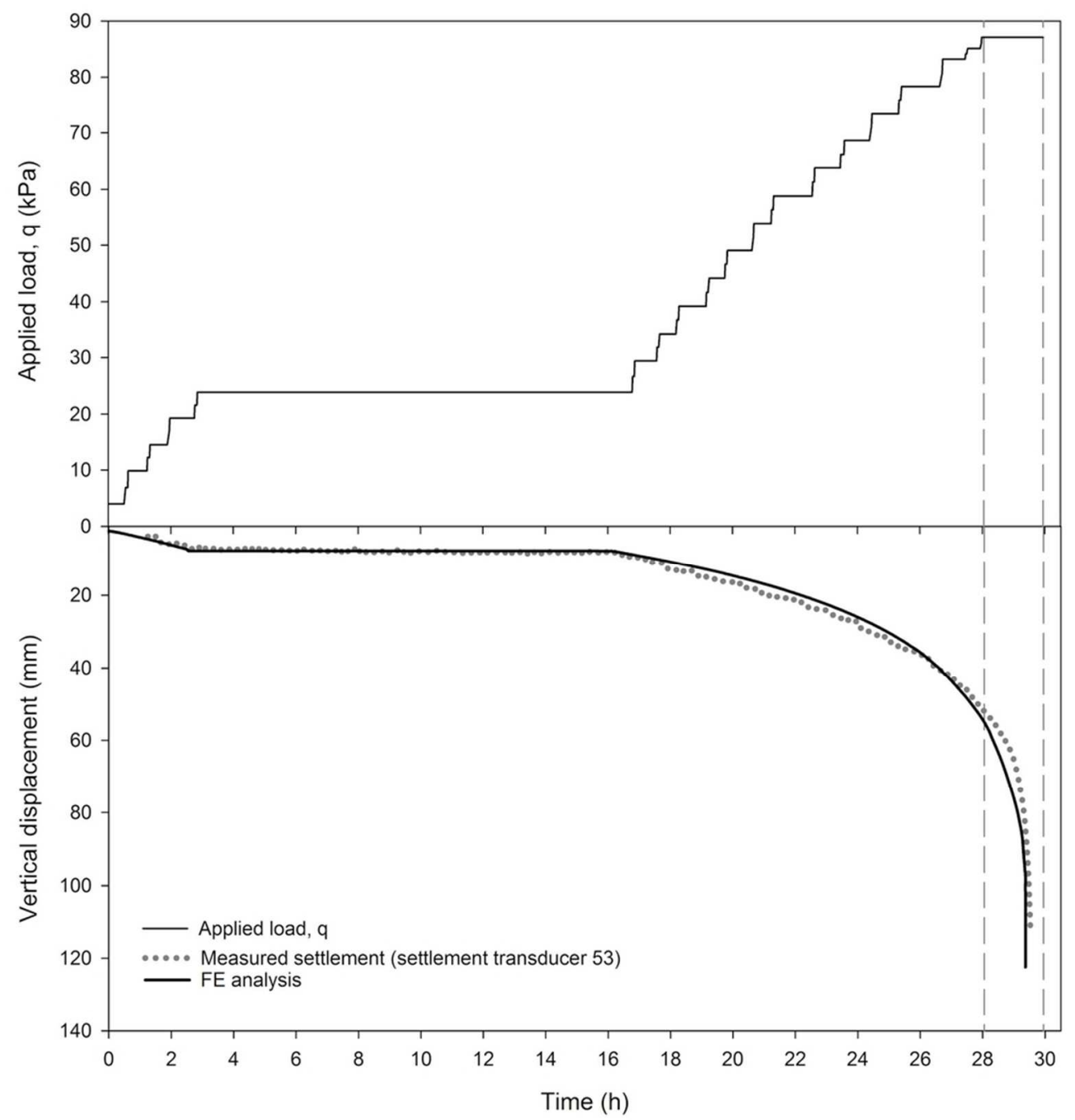

Fig. 19: Modelled versus observed Load-Time-Settlement.

Fig. 19

$85 \times 88 \mathrm{~mm}(300 \times 300 \mathrm{DPI})$ 


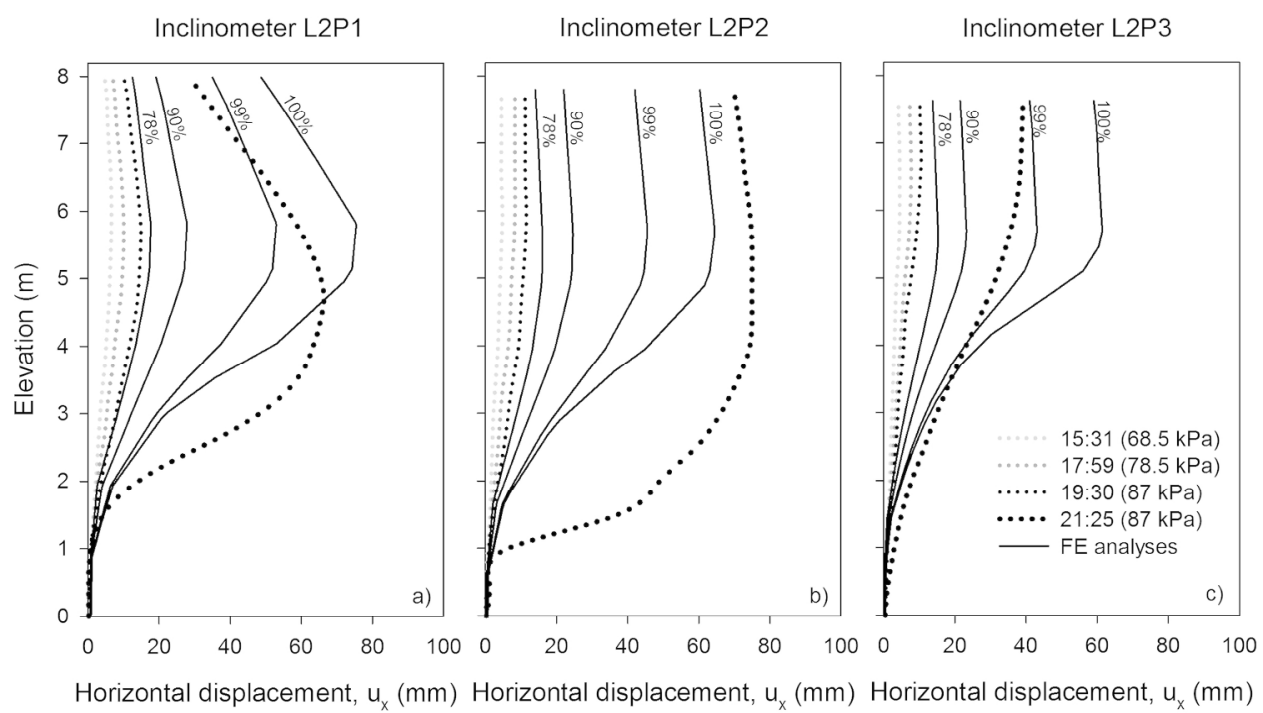

Fig. 20: Measured and modelled horizontal displacements for section A-A.

Fig. 20

$105 \times 60 \mathrm{~mm}(600 \times 600 \mathrm{DPI})$ 

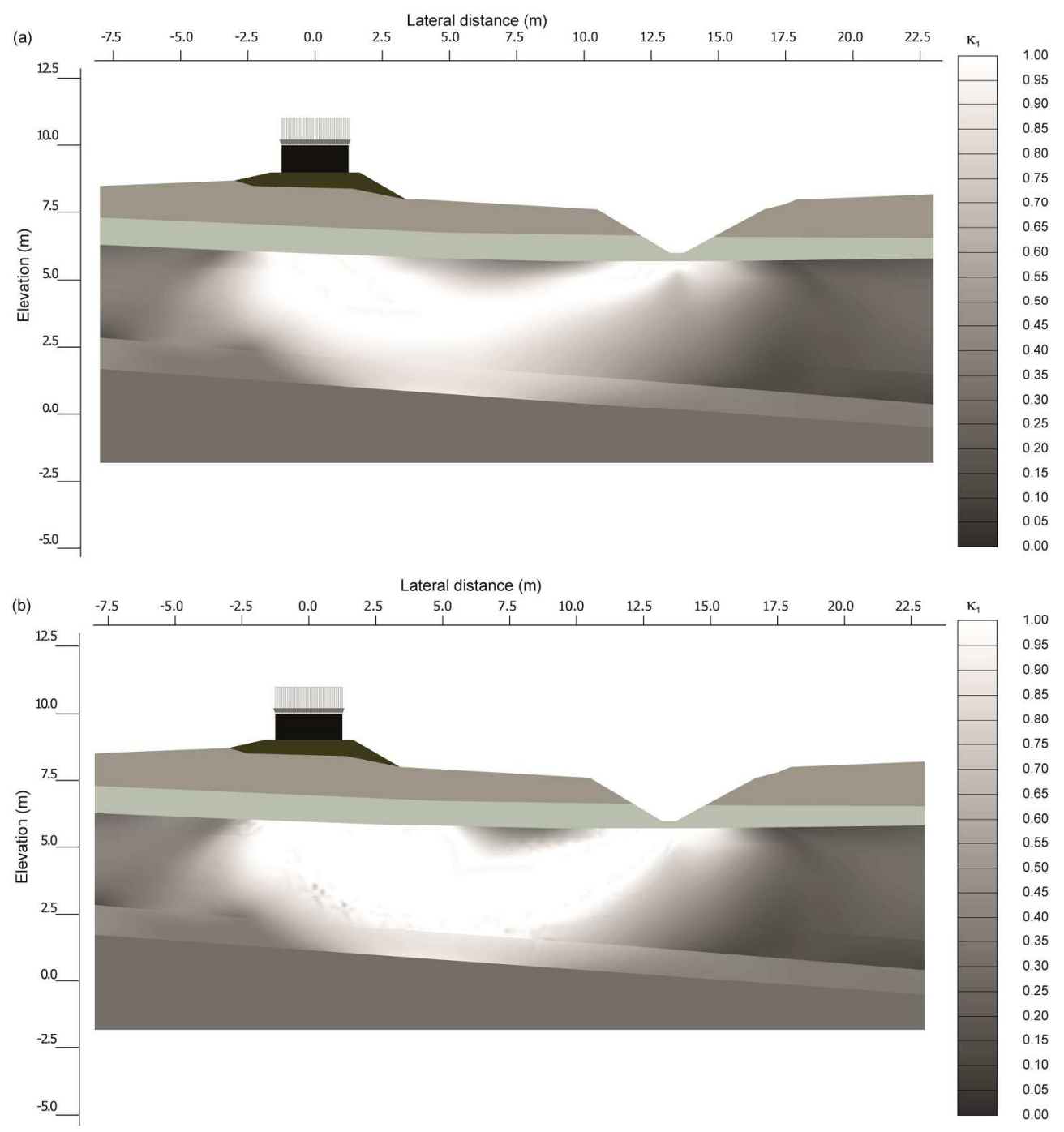

Fig. 21: Hardening parameter $\mathrm{k}_{1}$ for an embankment settlement of (a) $0.11 \mathrm{~m}$ (at peak state) and (b) $1 \mathrm{~m}$ (at large strain).

Fig. 21

$198 \times 215 \mathrm{~mm}(300 \times 300$ DPI $)$ 

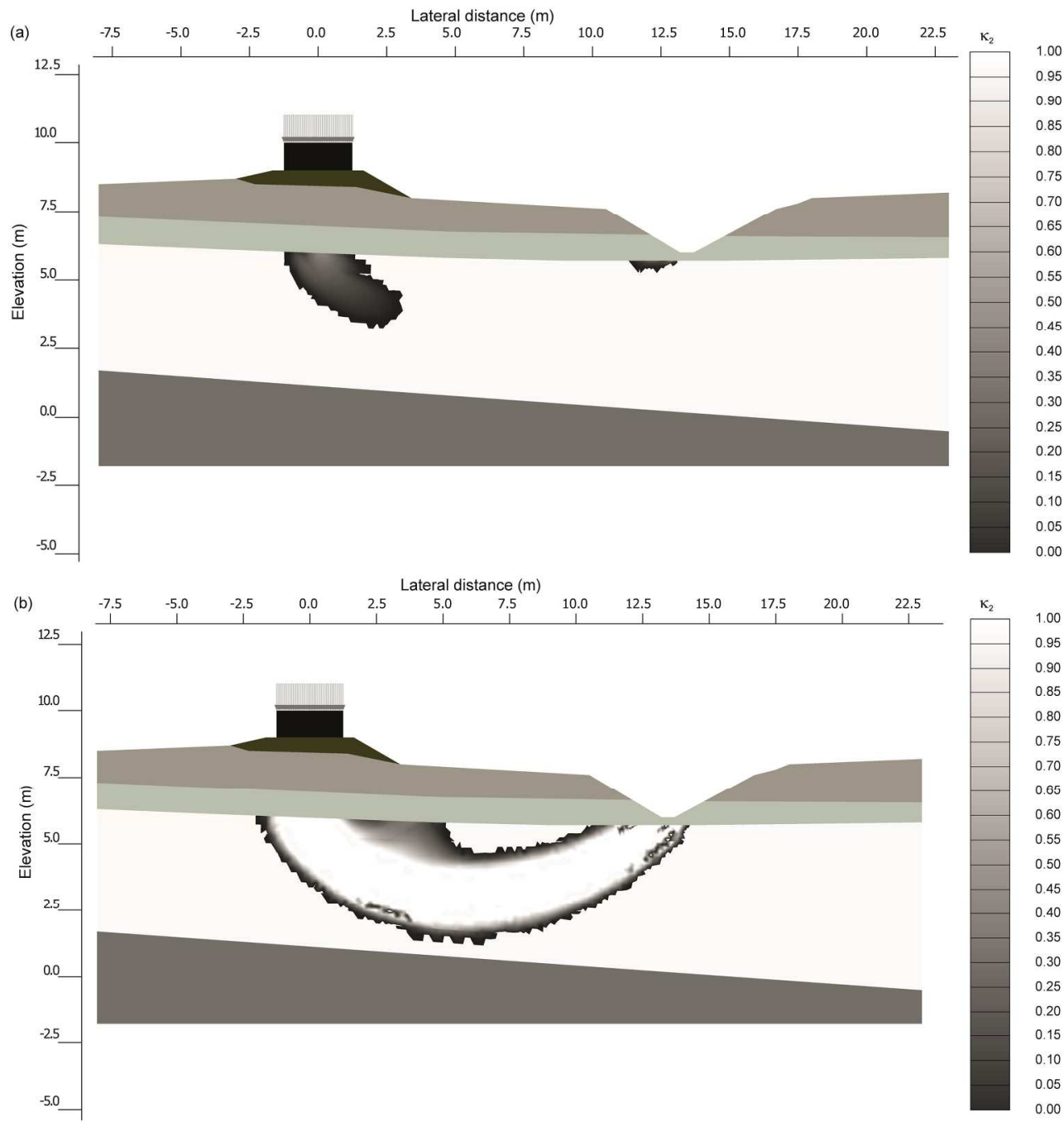

Fig. 22: Hardening parameter $\mathrm{k}_{2}$ for an embankment settlement of (a) $0.11 \mathrm{~m}$ (at peak state) and (b) $1 \mathrm{~m}$ (at large strain).

Fig. 22

$198 \times 211 \mathrm{~mm}(300 \times 300 \mathrm{DPI})$ 


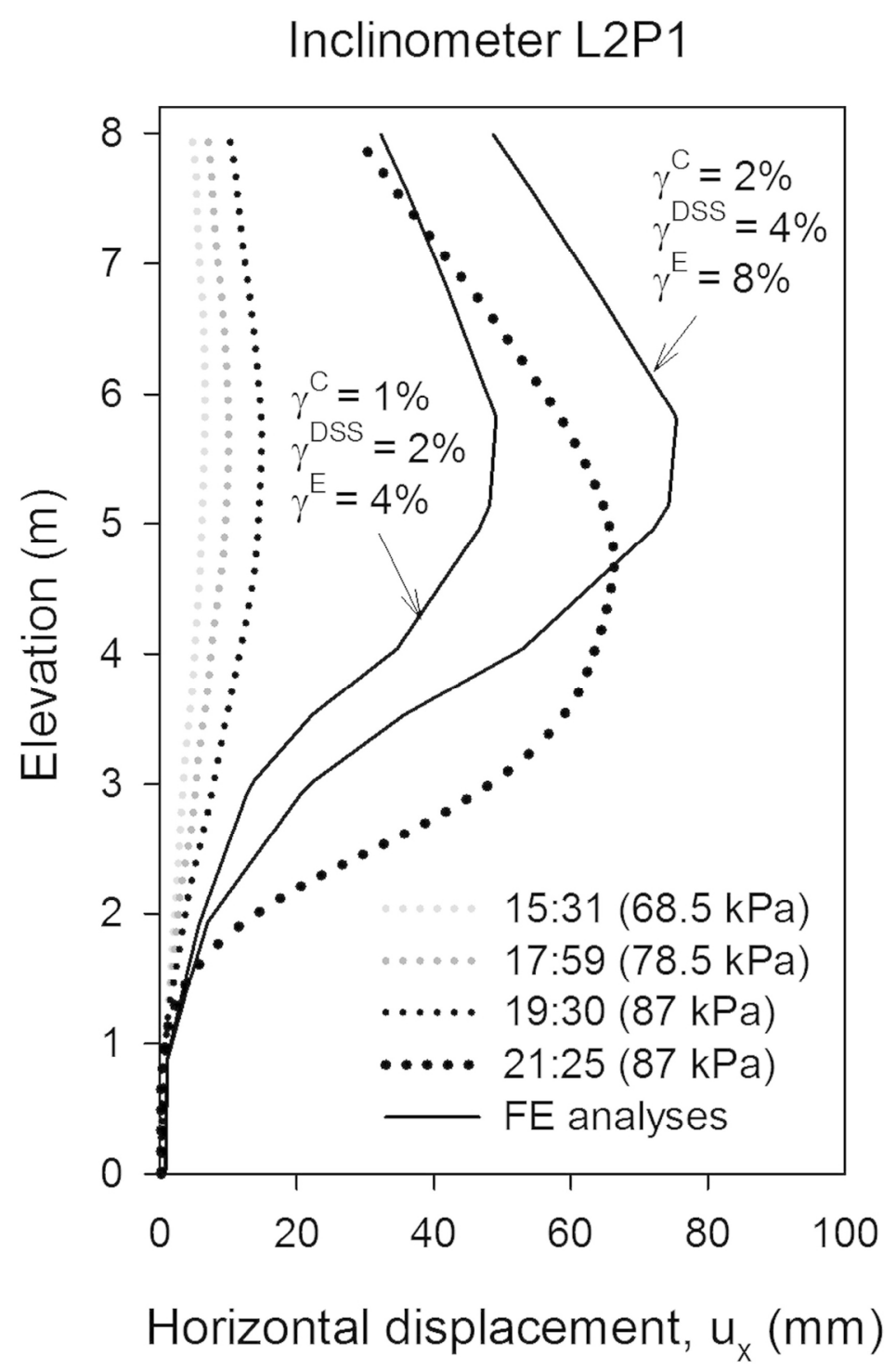

Fig. 23: Effect of input peak shear strains on horizontal displacements. Fig. 23 $119 \times 173 \mathrm{~mm}(300 \times 300 \mathrm{DPI})$ 